\title{
Climate change, growing season water deficit and vegetation activity along the north-south transect of eastern China from 1982 through 2006
}

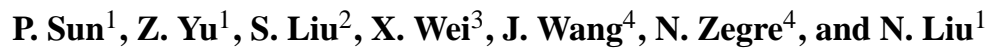 \\ ${ }^{1}$ Institute of Forest Ecology, Environment and Protection, Chinese Academy of Forestry, Beijing 100091, China \\ ${ }^{2}$ Chinese Academy of Forestry, Beijing 100091, China \\ ${ }^{3}$ University of British Columbia (Okanagan), 3333 University Way, Kelowna, BC V1V 1V7, Canada \\ ${ }^{4}$ West Virginia University, Morgantown, WV 26506-6125, USA \\ Correspondence to: P. Sun (sunpengsen@gmail.com)
}

Received: 7 May 2012 - Published in Hydrol. Earth Syst. Sci. Discuss.: 29 May 2012

Revised: 3 September 2012 - Accepted: 18 September 2012 - Published: 26 October 2012

\begin{abstract}
Considerable work has been done to examine the relationship between environmental constraints and vegetation activities represented by the remote sensing-based normalized difference vegetation index (NDVI). However, the relationships along either environmental or vegetational gradients are rarely examined. The aim of this paper was to identify the vegetation types that are potentially susceptible to climate change through examining their interactions between vegetation activity and evaporative water deficit. We selected 12 major vegetation types along the north-south transect of eastern China (NSTEC), and tested their time trends in climate change, vegetation activity and water deficit during the period 1982-2006. The result showed significant warming trends accompanied by general precipitation decline in the majority of vegetation types. Despite that the whole transect increased atmospheric evaporative demand $\left(\mathrm{ET}_{0}\right)$ during the study period, the actual evapotranspiration $\left(\mathrm{ET}_{\mathrm{a}}\right)$ showed divergent trends with $\mathrm{ET}_{0}$ in most vegetation types. Warming and water deficit exert counteracting controls on vegetation activity. Our study found insignificant greening trends in cold temperate coniferous forest (CTCF), temperate deciduous shrub (TDS), and three temperate herbaceous types including the meadow steppe (TMS), grass steppe (TGS) and grassland (TG), where warming exerted more effect on NDVI than offset by water deficit. The increasing growing season water deficit posed a limitation on the vegetation activity of temperate coniferous forest (TCF), mixed forest (TMF) and deciduous broad-leaved forest (TDBF). Differently, the growing
\end{abstract}

season brownings in subtropical or tropical forests of coniferous (STCF), deciduous broad-leaved (SDBF), evergreen broad-leaved (SEBF) and subtropical grasslands (STG) were likely attributed to evaporative energy limitation. The growing season water deficit index (GWDI) has been formulated to assess ecohydrological equilibrium and thus indicating vegetation susceptibility to water deficit. The increasing GWDI trends in CTCF, TCF, TDS, TG, TGS and TMS indicated their rising susceptibility to future climate change.

\section{Introduction}

Vegetation change (in form and/or function) as a result of climate change has been a long-time concern to the scientific community. Globally, warmer temperatures were previously expected to promote increases in evapotranspiration $\left(\mathrm{ET}_{\mathrm{a}}\right)$ and precipitation $(P)$ and thus lead to intensification of the global water cycle (Held and Soden, 2000; Huntington, 2006). However, the atmospheric evaporative demand was recently found declined over the past few decades, as measured by declining rates of pan evaporation in many locations because of the decreasing world wind speed, which exerts greater influence on energy-limited water-yielding catchments than water-limited ones (McVicar et al., 2012a). Large-scale vegetation activities (e.g., phenology and productivity) associated with evaporative water demand thus couple with regional hydrological cycles (IPCC, 2007). It 
was previously recognized that warmer temperatures have promoted increases in plant growth in northern high latitudes that associate with a lengthening of the active growing season (Myneni et al., 1997). Subsequently, Nemani et al. (2003) found the largest net primary production (NPP) increase was in tropical forest owing to increased solar radiation. Recently, Zhao and Running (2010) found that frequent regional droughts became the main constraint of plant growth and NPP in the last decade. Consequently, we questioned whether the warming climate will continue to increase vegetation activity, or if different climate constraints are more important or becoming important. There is a critical need to assess ecosystem susceptibility to climate change based on the long-term ecohydrological equilibrium and trend.

Temperature $(T)$ and $P$ are main forcing environmental factors governing vegetation change (Zhang et al., 2001; Sun et al., 2011), whereas their integrative effect for different ecosystems are rarely examined. For instance, increasing air temperature may prolong the length of growing season in many ecosystems (Piao et al., 2006a; Dragoni et al., 2011; Yu et al., 2010), but warming in isolation may not be beneficial to water-limited vegetation because it increases the evaporative demand and accelerates the ecosystem water loss. In a water-limited case, $P$ trends will have the largest impact on vegetation trends (Martiny et al., 2006). However, in an energy-limited case, radiation (Nemani et al., 2003) or other forms of energy input, e.g., wind speed (McVicar et al., 2010, 2012b), dominates the evapotranspiration. Therefore, the fully physically-based evapotranspiration model that captures main meteorological variables in its formation is more desirable (McVicar et al., 2012a), particularly for evaluating the vegetation ecohydrological responses to changing climates (Tan, 2007; Donohue et al., 2009; Scheiter and Higgins, 2009; Donohue et al., 2012). Vegetation change in coverage or composition and their relationships with local or regional water balance have been extensively studied at different spatial scales (Niehoff et al., 2002; Hundecha and Bárdossy, 2004; Sun et al., 2005, 2006; Zhang and Schilling, 2006; McVicar et al., 2007; Wei and Zhang, 2010; Zeng et al., 2012; Zang et al., 2012), particularly with dramatic forest disturbance such as intensive logging (Zhang et al., 1999; Andréassian, 2004; Brown et al., 2005) or forest fires (Lavabre et al., 1993). These significant forest disturbances dramatically change the vegetation coverage and consequently alter the hydrological processes.

With an increasing need to assess vegetation activity and hydrological responses under a changing climate, a quantitative green biomass indicator - normalized difference vegetation index (NDVI), which is associated to leaf chlorophyll content and green leaf density (Tucker and Sellers, 1986) has been widely used to evaluate large-scale vegetation activities, including aboveground primary production (Tan, 2007) or vegetation phenology (Piao et al., 2006a; Dragoni et al., 2011; Yu et al., 2010). One of the key advantages of remote sensing platforms is the availability of data to allow extrapolation not just in space, but also across the temporal domain, offering insight into pattern change and development through time (Wang et al., 2012). The seasonal dynamic of NDVI is capable of tracking seasonal water balance process in large catchments (Sun et al., 2008). Specifically, linking vegetation NDVI to catchment water balance components (i.e. actual evapotranspiration, $\mathrm{ET}_{\mathrm{a}}$ ) is an important measure in evaluating hydrological effect of gradual vegetation change. The NDVI data acquired from short revisit period remote sensing imagery, such as NOAA/AVHRR, SPOT/VEGETATION, and MODIS, can be used to examine vegetation phenological trends at large spatial scales with high temporal resolution (White et al., 1997, 2005; Beck et al., 2011) over a long time period. The long-term, fine temporal and spatial resolutions dataset of remote sensed NDVI promotes research into addressing the relationships between vegetation functioning and climate change. However, the majority of available literature only focused on the relationships between VI and precipitation (Méndez-Barroso et al., 2009) or temperature (Prasad et al., 2006, 2007). The widespread aridity index (AI) (Budyko, 1974; Arora, 2002; Suzuki et al., 2006), scaled drought condition index (SDCI) (Rhee et al., 2010) and temperature/vegetation condition index (TVDI) (Patel et al., 2009; Chen et al., 2011) only capture meteorological variables in their formations. In fact, the differential vegetation water assumption $\left(\mathrm{ET}_{\mathrm{a}}\right)$ in response to drought stress may hold clues about vegetation resilience to environment forcing, thus being indicative of ecosystem stability. The balance between $P$ and $\mathrm{ET}_{\mathrm{a}}$ determines ecosystem blue water yield, and has been widely used to determine land management alternatives in response to extreme climatic events or land-use changes around the world (Brown et al., 2008; Liu et al., 2009; Liu and Yang, 2010; Sun et al., 2011). Considering that drought or water deficit has become the main constraint of world plant growth (Zhao and Running, 2010), a novel hydrological equilibrium concept based index that associated with vegetation activities and functioning is thus needed to further evaluate ecosystem susceptibility. A novel index on the basis of hydrological equilibrium concept is essential to evaluate ecosystem susceptibility by associating with vegetation activities and functioning.

The objectives of our study were: (i) to confirm how the climate-vegetation spatial patterns and temporal trends are along the north-south transect of eastern China (NSTEC) and for the 12 major vegetation types; (ii) to examine the relationship between climate trend and vegetation activity that is represented by the growing season integrated NDVI, thus clarifying the dominant constraint of vegetation activity; and (iii) to formulate a novel index that represents growing season water deficit based on the hydrological balance concept. Based on the time trends in water deficit and vegetation activity, we identify the vegetation that is potentially susceptive to climate change. 
Table 1. Statistics for the twelve vegetation types that are distributed along the north-south transect of eastern China (NSTEC). Phenology events (onset dates of greening and dormancy) are derived from their respective seasonal dynamic curves of NDVI (Yu et al., 2010).

\begin{tabular}{|c|c|c|c|c|c|}
\hline Vegetation type & $\begin{array}{l}\text { Short } \\
\text { name }\end{array}$ & $\begin{array}{l}\text { Latitude } \\
\text { range }\end{array}$ & $\begin{array}{l}\text { Onset } \\
\text { date of } \\
\text { greening } \\
\text { (DOY) }\end{array}$ & $\begin{array}{l}\text { Onset } \\
\text { date of } \\
\text { dormancy } \\
\text { (DOY) }\end{array}$ & $\begin{array}{l}\text { Growing } \\
\text { season } \\
\text { length } \\
\text { (months) }\end{array}$ \\
\hline Cold temperate coniferous forest & CTCF & $48^{\circ} \sim 53^{\circ} \mathrm{N}$ & $123 \pm 6$ & $250 \pm 4$ & $4.2 \pm 0.3$ \\
\hline Temperate coniferous forest & TCF & $32^{\circ} \sim 42^{\circ} \mathrm{N}$ & $118 \pm 7$ & $268 \pm 6$ & $5.0 \pm 0.3$ \\
\hline Temperate mixed forest & TMF & $40^{\circ} \sim 47^{\circ} \mathrm{N}$ & $119 \pm 6$ & $260 \pm 4$ & $4.7 \pm 0.3$ \\
\hline Temperate deciduous broad-leaved forest & TDBF & $32^{\circ} \sim 53^{\circ} \mathrm{N}$ & $117 \pm 5$ & $262 \pm 4$ & $4.8 \pm 0.2$ \\
\hline Temperate deciduous shrub & TDS & $30^{\circ} \sim 50^{\circ} \mathrm{N}$ & $127 \pm 5$ & $260 \pm 3$ & $4.5 \pm 0.2$ \\
\hline Temperate meadow steppe & TMS & $35^{\circ} \sim 53^{\circ} \mathrm{N}$ & $138 \pm 6$ & $254 \pm 4$ & $3.9 \pm 0.3$ \\
\hline Temperate grass steppe & TGS & $36^{\circ} \sim 50^{\circ} \mathrm{N}$ & $145 \pm 8$ & $260 \pm 4$ & $3.8 \pm 0.3$ \\
\hline Temperate grassland & TG & $30^{\circ} \sim 42^{\circ} \mathrm{N}$ & $122 \pm 9$ & $265 \pm 5$ & $4.8 \pm 0.4$ \\
\hline Subtropical deciduous broad-leaved forest & SDBF & $25^{\circ} \sim 35^{\circ} \mathrm{N}$ & $100 \pm 7$ & $277 \pm 11$ & $5.9 \pm 0.5$ \\
\hline Subtropical evergreen broad-leaved forest & SEBF & $22^{\circ} \sim 31^{\circ} \mathrm{N}$ & $119 \pm 9$ & $316 \pm 10$ & $6.6 \pm 0.4$ \\
\hline Subtropical and tropical coniferous forest & STCF & $21^{\circ} \sim 34^{\circ} \mathrm{N}$ & $108 \pm 10$ & $270 \pm 12$ & $5.4 \pm 0.4$ \\
\hline Subtropical and tropical grassland & STG & $18^{\circ} \sim 34^{\circ} \mathrm{N}$ & $114 \pm 9$ & $297 \pm 10$ & $6.1 \pm 0.5$ \\
\hline
\end{tabular}

\section{Methods and datasets}

\subsection{North-south transect of eastern China and vegetation distribution}

The north-south transect of eastern China (NSTEC) was formally established in year 2000 as an IGBP (International Geosphere and Biosphere Program) terrestrial transect of the world. The ten-degree E-W and $3700 \mathrm{~km} \mathrm{~N}-\mathrm{S}$ transect stretches form the warm and humid tropical south to the cold semi-humid north. This transect is characterized by a strong $\mathrm{N}-\mathrm{S}$ temperature gradient and an E-W precipitation gradient. Mean annual precipitation (MAP) of the NSTEC varied from $500 \mathrm{~mm} \mathrm{a}^{-1}$ to $1800 \mathrm{~mm} \mathrm{a}^{-1}$, and mean annual temperature (MAT) was from about $1{ }^{\circ} \mathrm{C}$ to $22^{\circ} \mathrm{C}$. The great spatial variations of solar energy and water availability are the dominant causes of ecosystem distribution along the NSTEC. We selected twelve major natural vegetation types distributed along the transect from the north to the south (Table 1).

\subsection{Datasets and spatial interpolation}

The digitized 1:1000000 vegetation map of the NSTEC was originated from an open electronic vegetation map published by the Institute of Botany, Chinese Academy of Science in 2007. This vegetation map includes 55 vegetation types, 960 types of formations, and more than 2000 dominant plant species on a national scale. Twelve typical natural ecosystems within the NSTEC have been selected based on the above vegetation map. The 12 ecosystems were clipped and merged into a set of scattered polygons. In order to minimize the "edge effect" (i.e., if the area outside the ecosystem boundary is a disturbed or unnatural system, the natural ecosystem can be seriously affected for some distances from the edge), two steps of GIS spatial process were conducted:
(1) discard polygons less than $64 \mathrm{~km}^{2}$ in size, and (2) apply buffering to identify the inside region for a fixed distance $(4 \mathrm{~km})$ away from the polygons' boundaries. The new vegetation map was therefore created, which is much smaller in size after the above two steps. The above procedures were used to ensure the selected vegetation types are accurate with clear boundaries, and would significantly reduce the NDVI noise in subsequent overlay analysis. Only natural vegetation types were selected in this study, and all human influenced areas including urban area and farmland were excluded.

The climate dataset is from China Meteorological Administration (CMA) based on a total of 741 standard stations across China. The ANUSPLIN package (Ver.4.1; Australian National University, Center for Resources and Environmental Studies, Canberra, Australia), which supports transparent analysis and interpolation of noisy multi-variate data using thin plate smoothing splines (Hutchinson and Gessler, 1994), was employed to interpolate climate surfaces on the national scale. ANUSPLIN has been widely applied on spatial interpolation of hydro-meteorological variables and has enhanced utility over other spatial interpolation approaches such as kriging (McVicar et al., 2007, 2010). In this study, a tri-variate partial thin plate spline incorporating a bi-variate thin plate spline as a function of longitude, latitude and constant linear dependencies on elevation were used in simulating surfaces of monthly precipitation and temperature (Sun et al., 2008).

Biweekly NDVI data were derived from the AVHRR sensor aboard NOAA polar orbiting satellites (specifically NOAA 7, 9, 11, 14, and 16), and were calculated from AVHRR visible and infrared bands as:

$\mathrm{NDVI}=\left(R_{\mathrm{nir}}-R_{\mathrm{r}}\right) /\left(R_{\mathrm{nir}}+R_{\mathrm{r}}\right)$, 
where $R_{\mathrm{r}}$ is the spectral reflectance in red region (550$700 \mathrm{~nm})$ and $R_{\text {nir }}$ is the spectral reflectance in near infrared region $(730-1000 \mathrm{~nm})$. NDVI data used in this study were derived from the open source of GIMMS (Global Inventory Modeling and Mapping System) from NASA's Goddard Space Flight Center, as described by Beck et al. (2011). The calibration based on invariant desert targets has been applied to the original data to minimize the effects of sensor degradation. The NDVI monthly data at $8 \mathrm{~km}$ spatial resolution was generated from previously processed biweekly NDVI composites using the maximum value compositing procedure to minimize the effects of cloud contamination (e.g., McVicar and Bierwirth, 2001). A kriging interpolation removed noise and attenuated the effect of cloudy and missing pixels for spatially-averaged NDVI of 12 natural ecosystems in NSTEC (Table 1).

The time-integrated NDVI (TI-NDVI) can be a metric of vegetation activity (Jia et al., 2006). We chose not to use average annual NDVI because the non-growing season snow pack will contaminate information on the vigorousness of vegetation growth in growing season. Zhao et al. (2001) found out that in China the relationship between annual total NDVI and precipitation and temperature is insupportable in ecological theory, but it is supportable when only the growing season data are used (i.e., April to October). Therefore, in this study we use the cumulative value of NDVI during growing season (from May to October). The duration of growing season was decided according to our previous phenological analysis (Yu et al., 2010) for all vegetation types along the transect (Table 1).

$\mathrm{TI}-\mathrm{NDVI}_{\mathrm{g}}=\sum_{i=5}^{10} \mathrm{NDVI}_{i}$

where TI-NDVI $\mathrm{g}$ is the time integrated NDVI for growing season, $i$ is month of the year, and NDVI-value is the spatial average of specific vegetation type. Correspondingly, the accumulated growing degree days (AGDD) is defined by:

$\mathrm{AGDD}=\sum_{t=i}^{i} \mathrm{GDD}\left(\right.$ if $\left.\mathrm{GDD}_{t}>0{ }^{\circ} \mathrm{C}\right)$,

where $t$ is the day of the year (DOY), and $i$ and $j$ are the beginning and end date of the year (DOY), respectively, for the growing season. The growing degree days (GDD) is the summation of days when near-surface air temperature is above $0{ }^{\circ} \mathrm{C}$ over the growing season.

\section{$2.3 \quad \mathrm{ET}_{\mathrm{p}}$ and $\mathrm{ET}_{\mathrm{a}}$ algorithm}

Several methods can be used to calculate or simulate surface evapotranspiration (ET). However, it remains one of the most difficult water balance components to quantify, particularly at large scales (Mu et al., 2007). A couple of recent studies advocate that the use of a "fully physically-based"

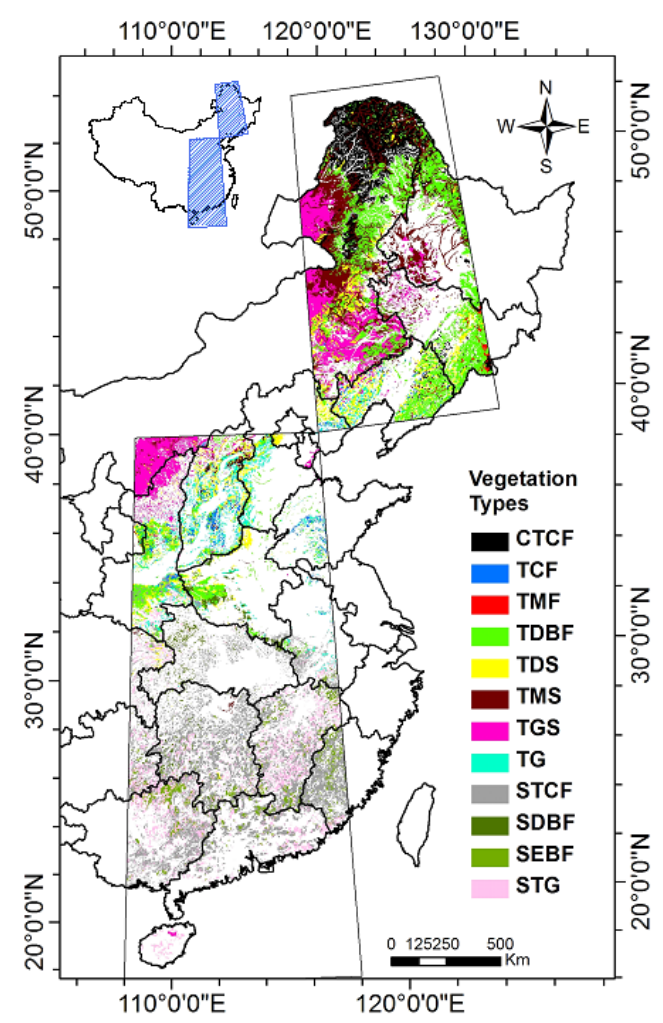

Fig. 1. Twelve major natural vegetation types and their spatial distribution along the north-south transect of eastern China (NSTEC).

formulation of $\mathrm{ET}_{\mathrm{p}}$ is more desirable than either Thornthwaite or Prestley-Taylor formations (McVicar et al., 2012a, b; Thomas, 2008). These studies highlighted the importance of wind speed $(u)$ contributing to declining rates of world evaporative demand. Thus, in this study, we use FAO-56 (Allen et al., 1998) to calculate PET in the specific form of reference ET $\left(\mathrm{ET}_{0}\right)$, which assumes fixed values for crop surface resistance, albedo and crop height of $70 \mathrm{~s} \mathrm{~m}^{-1}, 0.23$ and $0.12 \mathrm{~m}$, respectively. The following crop reference evapotranspiration $\left(\mathrm{ET}_{0}\right)$ is from Allen et al. (1998):

$\mathrm{ET}_{0}=\frac{0.408 \Delta\left(R_{\mathrm{n}}-G\right)+\gamma \frac{900}{T_{\mathrm{a}}+273} u_{2} D}{\Delta+\gamma\left(1+0.34 u_{2}\right)}$,

where $\Delta$ is the slope of the saturation vapor pressure curve $\left(\mathrm{kPa}^{\circ} \mathrm{C}^{-1}\right) ; R_{\mathrm{n}}$ is the net radiation at the surface $\left(\mathrm{MJ} \mathrm{m}^{-2} \mathrm{~d}^{-1}\right) ; G$ is the ground heat flux $\left(\mathrm{MJ} \mathrm{m}^{-2} \mathrm{~d}^{-1}\right) ; \gamma$ is the psychrometric constant $\left(\mathrm{kPa}^{\circ} \mathrm{C}^{-1}\right) ; T_{\mathrm{a}}$ is the mean daily air temperature, that is $T_{\mathrm{a}}=\left(T_{\max }+T_{\min }\right) / 2\left({ }^{\circ} \mathrm{C}\right)$, where $T_{\max }$ and $T_{\min }$, respectively, are the daily maximum and minimum air temperatures $\left({ }^{\circ} \mathrm{C}\right) ; u_{2}$ is the daily average wind speed at $2 \mathrm{~m}$ above ground level $\left(\mathrm{m} \mathrm{s}^{-1}\right)$; and $D$ is the saturation vapor pressure deficit $(\mathrm{kPa})=e_{\mathrm{S}}-e_{\mathrm{a}}$, with $e_{\mathrm{S}}$ being the saturation vapor pressure $(\mathrm{kPa})$ and $e_{\mathrm{a}}$ the actual vapor pressure $(\mathrm{kPa})$.

The mean annual evapotranspiration can be modeled using Budyko method by only considering water availability 
and atmospheric demand as dominant controls. Zhang et al. (2001) further developed the Budyko modeling framework by introducing additional controls such as rainfall seasonality and vegetation characteristics (Donohue et al., 2007).

$$
\frac{\mathrm{ET}_{\mathrm{a}}}{P}=\frac{1+w \frac{\mathrm{ET}_{\mathrm{p}}}{P}}{1+w \frac{\mathrm{ET}_{\mathrm{p}}}{P}+\left(\frac{\mathrm{ET}_{\mathrm{p}}}{P}\right)^{-1}},
$$

where $\mathrm{ET}_{\mathrm{a}}$ is the actual evapotranspiration, and $\mathrm{ET}_{\mathrm{p}}$ the the potential evapotranspiration; in this study we use the specific form $\mathrm{ET}_{0}$ for the whole transect. $w$ is the plant-available water coefficient which ranges between 0.5 and 2.0 for grassland, shrubland and forest.

\subsection{Ecosystem-specific time series and trend analysis}

We first used layer stacking to build new multiband image files based on spatial data surfaces of each parameter, including temperature, precipitation, NDVI, ET and PET surfaces. The 300-band stack included monthly data surfaces covering $25 \mathrm{yr}$ with $8 \mathrm{~km}$ resolution. Spatial statistical analysis was then conducted for each vegetation type, including mean, stand deviation and range of monthly data series from the multiband images. The spatially averaged monthly data series were finally extracted from multiband images according to the vegetation types. To further evaluate the time trends for different vegetation types of the NSTEC, the seasonal MannKendall (SMK) test was applied to each vegetation type. The SMK test is a non-parametric test for the detection of trend in a time series. The SMK test first analyzed the data subsets based on the observation ranks of the subsets across years. The test statistic was then calculated by summing the number of times in a particular year that this sum is higher than any previous years (Beurs and Henebry, 2004; Sun et al., 2008).

\subsection{Definition of growing water deficit index (GWDI)}

The widespread aridity index (AI) (Budyko, 1974) was defined as:

$\mathrm{AI}=P / \mathrm{ET}_{0}$.

This gives the basic idea of hydrological conditions with in the study area. AI $>1$ indicates humid conditions where water availability $(P)$ exceeds atmosphere water demand $\left(\mathrm{ET}_{0}\right)$, and $\mathrm{AI}<1$ indicates dry conditions (Thomas, 2008). However, the actual evapotranspiration $\left(\mathrm{ET}_{\mathrm{a}}\right)$, which represents the hydrological response from vegetation, was not explicitly defined in the AI. With an attempt to improve the ecological implication, we defined a novel water balance-based index, the growing season water deficit index (GWDI), which describes the balance between evaporative water demand gap (the difference between actual and potential evapotranspirations) and water remaining (the difference between precipitation and actual evapotranspiration) in the ecosystem for the growing season (Eq. 3). Different from AI that captures mainly the meteorological variables, GWDI integrates not only the meteorological variables, but also the variable for vegetation actual water assumption, which is associated with vegetation activity. In order to highlight the $\mathrm{ET}_{\mathrm{a}}$ importance, the index is defined only by seasonal growing.

$\mathrm{GWDI}=\frac{\left(\mathrm{ET}_{\mathrm{p}}-\mathrm{ET}_{\mathrm{a}}\right)}{\left(P-\mathrm{ET}_{\mathrm{a}}\right)}$,

where the $\mathrm{ET}_{\mathrm{p}}, \mathrm{ET}_{\mathrm{a}}$ and $P$ were totaled for growing season. Assuming steady-state water balance, we chose not to define ecosystem water storage change $\left(d S_{\mathrm{W}} / d_{t}\right)$ and stream flow $(Q)$ in GWDI for the three main hydrologic conditions. (i) Arid condition: The soil water storage is usually very low, and the interception evaporation, soil evaporation and plant transpiration are highly dependent on within-growing season precipitation. (ii) Humid condition: The soil water storage reaches maximum, and $\mathrm{ET}_{\mathrm{a}}$ becomes energy limited as described in McVicar et al. (2012b). In the above two cases, the carry-over of water from the previous year(s) that is available for plant transpiration and soil evaporation during the whole growing-season is assumed to be negligible (Richard et al., 2008). (iii) Semiarid/semihumid condition: Similar with "equitant" climate, as defined by McVicar et al. (2012b), according to dominant limitations (water or energy limitations) $\mathrm{ET}_{\mathrm{a}}$ typically vacillates seasonally. In this case, the $d S_{W} / d_{t}$ maybe more influential than in the first two cases, but we still can assume the effect of soil water carry-over is short term, within the first month of growing season, for the whole growing season is negligible.

Figure 2 describes the GWDI response curve to precipitation. The vertical solid line represents the balance precipitation that corresponds to GWDI $=1$, the same condition with $\mathrm{AI}=1$ (assuming $P=\mathrm{ET}_{0}$ ), and is likely the "equitant" condition defined by McVicar et al. (2012b) according the dominant limitations of evapotranspiration. The boundaries of the semiarid/semihumid condition are somewhat arbitrary, defined here by $+100 \%(\mathrm{GWDI}=2.0)$ and $-50 \%$ $(\mathrm{GWDI}=0.5)$ from the case where GWDI $=1.0$. For "equitant" condition, soil water storage may play a role in compensating the influence of short-term water deficit to vegetation $\mathrm{ET}_{\mathrm{a}}$. The left-shifted $(\mathrm{a} \rightarrow \mathrm{b})$ balance line (dash-line curve in Fig. 2) represents that the potential influences of soil water storage (e.g., $100 \mathrm{~mm} d S_{W} / d_{t}$ is equivalent to $100 \mathrm{~mm}$ precipitation) on GWDI. In extreme dry condition $(\mathrm{GWDI}>2.0)$, the plant growth and $\mathrm{ET}_{\mathrm{a}}$ are water-limited $\left(P-\mathrm{ET}_{\mathrm{a}} \rightarrow 0\right.$ and GWDI $\left.\rightarrow \infty\right)$. The significant upward trend in GWDI and a subsequent browning trend in vegetation may indicate the rising susceptibility to environmental change. In extreme wet condition $(\mathrm{GWDI}<0.5)$, the plant growth and $\mathrm{ET}_{\mathrm{a}}$ are energy-limited $\left(\mathrm{ET}_{\mathrm{p}}-\mathrm{ET}_{\mathrm{a}} \rightarrow 0\right.$ and GWDI $\rightarrow 0$ ). The ecosystem retains more than demands water resources which are available for plant use, and saturation excess results in runoff (blue water) (Calder, 2005; Liu et al., 2009). 
Table 2. Seasonal Mann-Kendall (SMK) trend tests of temperature by vegetation types from 1982 to 2006.

\begin{tabular}{|c|c|c|c|c|c|c|c|c|c|c|c|c|}
\hline Season & CTCF & TCF & $\mathrm{TMF}$ & TDBF & TDS & TMS & TGS & TG & STCF & STG & SDBF & SEBF \\
\hline \multicolumn{13}{|l|}{ Monthly } \\
\hline Jan & 0.3 & 1.0 & 1.4 & 1.3 & 1.1 & 0.7 & 0.8 & 1.9 & 1.4 & 1.3 & 0.3 & 1.3 \\
\hline Feb & 1.5 & $3.5^{\mathrm{b}}$ & $2.2^{\mathrm{a}}$ & $2.0^{\mathrm{a}}$ & $2.8^{\mathrm{b}}$ & 1.8 & $2.7^{b}$ & $3.6^{\mathrm{b}}$ & $3.0^{\mathrm{b}}$ & $2.1^{\mathrm{a}}$ & $2.9^{\mathrm{b}}$ & $2.0^{\mathrm{a}}$ \\
\hline Mar & 1.1 & $3.7^{\mathrm{b}}$ & 1.3 & 1.0 & $2.0^{\mathrm{a}}$ & 0.8 & 1.7 & $3.3^{\mathrm{b}}$ & $3.4^{\mathrm{b}}$ & $2.8^{\mathrm{b}}$ & $3.4^{\mathrm{b}}$ & $2.0^{\mathrm{a}}$ \\
\hline Apr & 0.4 & $2.2^{\mathrm{a}}$ & 1.3 & 0.9 & 1.5 & 1.5 & 1.8 & $2.2^{\mathrm{a}}$ & 1.9 & $2.6^{\mathrm{b}}$ & $2.2^{\mathrm{a}}$ & $2.7^{\mathrm{b}}$ \\
\hline May & 0.5 & 1.6 & 1.3 & 1.3 & $2.0^{\mathrm{a}}$ & 1.4 & $2.0^{\mathrm{a}}$ & $2.0^{\mathrm{a}}$ & 0.8 & 0.9 & 1.0 & 1.5 \\
\hline Jun & 0.4 & $3.1^{\mathrm{b}}$ & $3.0^{\mathrm{b}}$ & 1.7 & $2.4^{\mathrm{a}}$ & 1.5 & $2.5^{\mathrm{b}}$ & $3.1^{b}$ & $3.3^{\mathrm{b}}$ & $2.0^{\mathrm{a}}$ & $3.3^{\mathrm{b}}$ & 0.8 \\
\hline Jul & $2.5^{\mathrm{b}}$ & $3.1^{\mathrm{b}}$ & $3.1^{\mathrm{b}}$ & $2.1^{\mathrm{a}}$ & $2.8^{\mathrm{b}}$ & $2.9^{\mathrm{b}}$ & $3.6^{\mathrm{b}}$ & $3.0^{\mathrm{b}}$ & $3.5^{\mathrm{b}}$ & 1.7 & $2.4^{\mathrm{a}}$ & 0.1 \\
\hline Aug & 1.3 & 1.7 & -0.3 & -0.7 & 0.7 & 1.8 & $2.2^{\mathrm{a}}$ & $1.5^{\mathrm{b}}$ & 0.4 & 0.6 & -0.2 & 0.1 \\
\hline Sep & 1.4 & 1.7 & $3.2^{\mathrm{b}}$ & $3.1^{\mathrm{b}}$ & $3.1^{\mathrm{b}}$ & $3.3^{\mathrm{b}}$ & $3.5^{\mathrm{b}}$ & $2.6^{\mathrm{b}}$ & 1.7 & 1.8 & 1.5 & 0.8 \\
\hline Oct & 1.1 & 0.4 & 1.5 & 1.0 & 1.1 & 1.5 & 0.9 & 1.2 & 0.4 & 0.5 & 0.7 & 0.6 \\
\hline Nov & -0.6 & 1.8 & 1.1 & 0.7 & 0.8 & -0.3 & 0.5 & 1.9 & 1.4 & 1.6 & 0.7 & $2.0^{\mathrm{a}}$ \\
\hline Dec & -0.6 & 1.3 & -0.3 & -0.4 & -0.2 & -1.5 & -0.2 & 1.5 & 0.9 & 0.9 & 0.6 & 0.8 \\
\hline \multicolumn{13}{|c|}{ Growing season } \\
\hline AGDD & $2.1^{\mathrm{a}}$ & $3.5^{\mathrm{b}}$ & $3.8^{\mathrm{b}}$ & $2.9^{\mathrm{b}}$ & $3.4^{\mathrm{b}}$ & $4.0^{\mathrm{b}}$ & $4.2^{\mathrm{b}}$ & $3.2^{\mathrm{b}}$ & $3.0^{\mathrm{b}}$ & $2.1^{\mathrm{a}}$ & $2.6^{\mathrm{b}}$ & 1.6 \\
\hline $\begin{array}{l}\text { Annual } \\
\text { MAT }\end{array}$ & 1.1 & $4.0^{\mathrm{b}}$ & $2.7^{\mathrm{b}}$ & $4.2^{\mathrm{b}}$ & $4.1^{\mathrm{b}}$ & $3.7^{\mathrm{b}}$ & $2.6^{\mathrm{b}}$ & $3.5^{\mathrm{b}}$ & $3.5^{\mathrm{b}}$ & $3.7^{\mathrm{b}}$ & $4.1^{\mathrm{b}}$ & $3.7^{b}$ \\
\hline
\end{tabular}

${ }^{a}$ Significant at $P<0.05 .{ }^{\mathrm{b}}$ Significant at $P<0.01$. A positive SMK statistic value denotes an upward trend and a negative one denotes a downward trend.

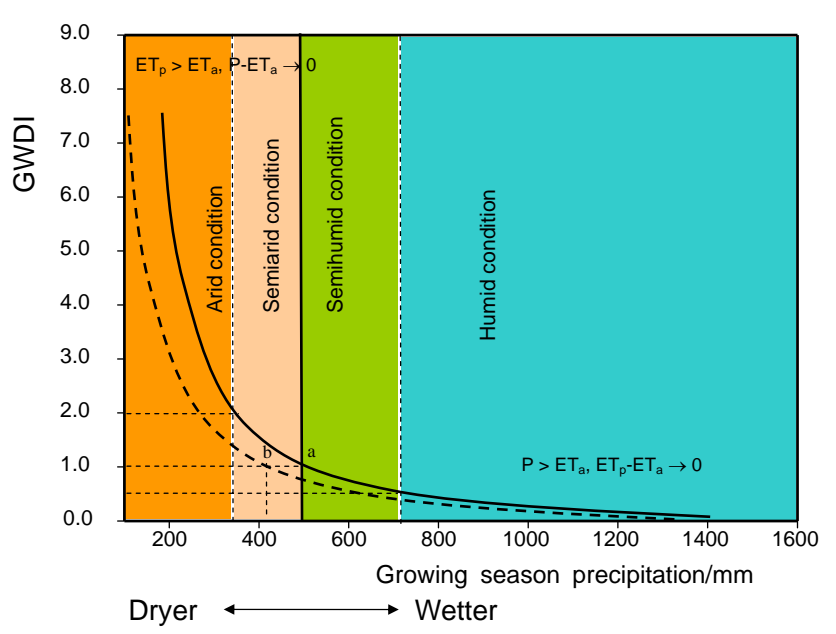

Fig. 2. The growing season water deficit (GWDI) response curve to precipitation. The vertical solid line represents the hydrological balance precipitation that corresponds to GWDI $=1$, the same condition with aridity index $(\mathrm{AI})=1$ (assuming $\left.P=\mathrm{ET}_{0}\right)$. The semiarid and semihumid conditions correspond to the "equitant" condition defined by McVicar et al. (2012b). The left-shifted $(a \rightarrow b)$ balance line (dash-line curve) represents the potential influences of soil water storage change to GWDI.

\section{Results}

\subsection{Monthly, growing seasonal and annual trends}

Figure 3 demonstrats the contrasting spatial patterns and change rates for mean growing season temperature (MGT), mean growing season precipitation (MGP) and time integrated NDVI for growing season (TI-NDVI ${ }_{g}$ ) during the study period. The MGT showed general increase along NSTEC with a rate of $0.04 \pm 0.02^{\circ} \mathrm{yr}^{-1}$. Warming was especially remarkable within latitude $36-50^{\circ} \mathrm{N}$ (Fig. 3a). The MGP showed high spatial variation along the NSTEC that decreased in the majority area of the transect by a maximum of $-30 \%$ (Fig. 3a), and increased in much smaller areas of the mid-eastern and southern portions of the transect by a maximum of $30 \%$. On average, the entire transect experienced up to $-6.3 \%$ MGP decline during the study period. TI-NDVI $_{\mathrm{g}}$ demonstrated significant increase $(10 \sim 40 \%)$ in the middle of the transect within latitudes 30 to $50^{\circ} \mathrm{N}$, but in the lower latitude regions showed remarkable browning trends. On average, the entire transect TI-NDVI $I_{g}$ showed a slight increase of $1.24 \%$ (Fig. 3c).

The time trends in MAT and AGDD for the majority of vegetation types along NSTEC are consistently positive $(P<0.01)$ over the study period, except for the MAT in cold temperate coniferous forests and AGDD in subtropical evergreen broad-leaved forest which are showing upward while not significant trends (Table 2). The significant warming trends usually occurred from February to September. Nine vegetation types, including TCF, TMF, TDS, TGS, 

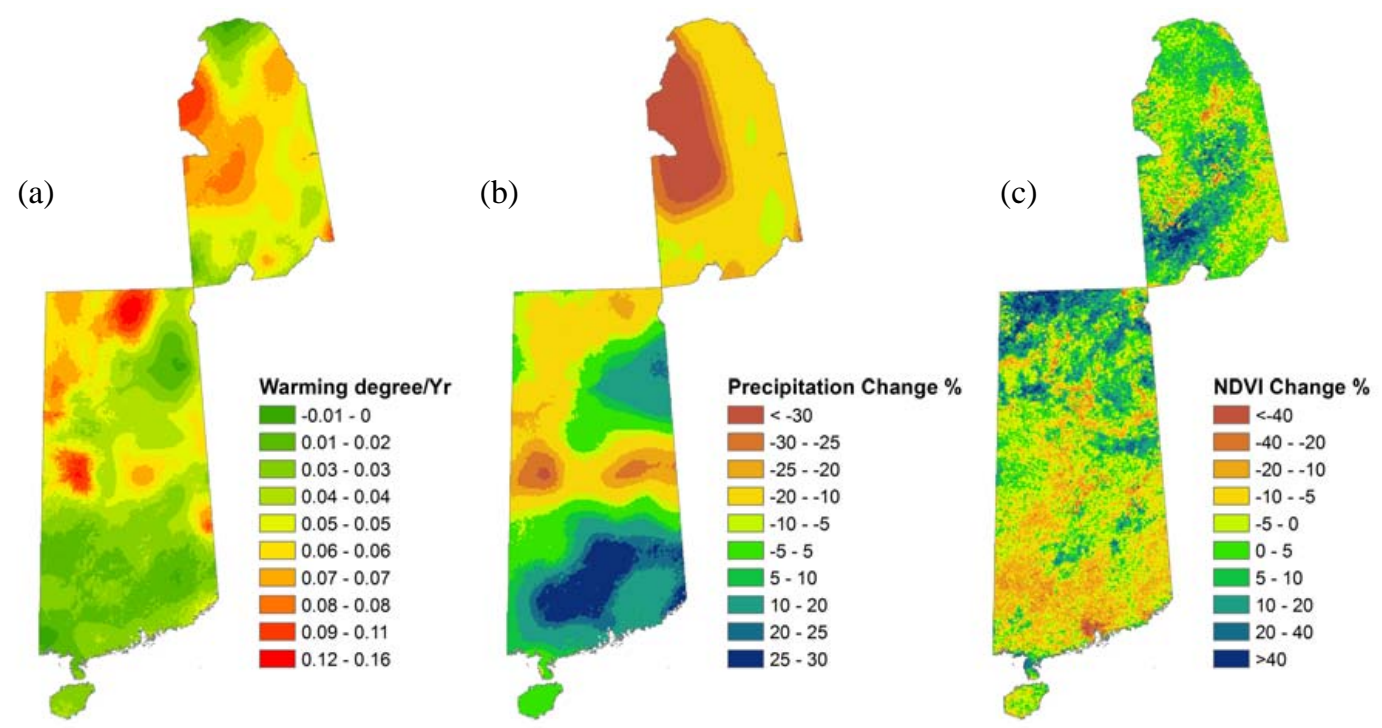

Fig. 3. (a) Averaged change rate (degree $\mathrm{yr}^{-1}$ ) of mean growing season temperature (MGT) from 1982 to 2006 . (b) Averaged change rate (\%) of mean growing season precipitation (MGP) from 1982 to 2006. (c) Averaged change rate (\%) of time integrated NDVI for growing season (TI-NDVI ) from 1982 to 2006.

TG, STCF, STG, SDBF and SEBF, suffered from no less than four months of significant warming every year. There were one or two months of significant warming in summer time (July to September) for the remaining types: CTCF, TDBF and TMS (Table 2).

The SMK test showed that the majority of vegetation types along the NSTEC experienced mean annual precipitation (MAP) decline during the study period, whereas half of them (CTCF, TMF, TDS, TMS, TG and SDBF) were statistically significant in their downward trends. Only STCF and STG showed slightly upward but insignificant trends (Table 3). The growing season precipitation (MGP) showed consistent downward trends with MAP in most vegetation types, except for STCF and SEBF which showed divergent but insignificant trends. Seasonal precipitation declined occurred during roughly March to September, particularly in September. The precipitation in TCF, TG and STCF decreased significantly in March and CTCF in August, whereas most other types, including TMF, TDBF, TDS, TMS, STG and SEBF, decreased significantly in September.

Among the vegetation types that showed upward TI$\mathrm{NDVI}_{\mathrm{g}}$ trends, only TG was significant $(P=0.02)$. The other two herbaceous types (TMS and TGS), the cold temperate coniferous forest (CTCF) and temperate deciduous shrub (TDS) showed positive but insignificant trends (Table 4). The rest of the vegetation types showed downward TI-NDVI $\mathrm{g}_{\mathrm{g}}$ trends, including significant trends for TCF $(P=0.04)$, SEBF $(P=0.001)$ and STG $(P=0.008)$, and insignificant trends for TMF $(P=0.24)$, TDBF $(P=$ $0.19)$, STCF $(P=0.48)$ and SDBF $(P=0.1)$. Regarding the monthly NDVI trends, the southern subtropical types including STG, SDBF and SEBF showed four to five months of decrease that centered in August, and the cold temperate forest types CTCF exhibited a strong non-growing season decrease in November and December.

The majority of the 12 transect vegetation types showed upward annual potential evapotranspiration $\left(\mathrm{ET}_{\mathrm{p}}\right)$ during the study period, only TMF and STG showed insignificant downward trend (Table 5). For all vegetation types, the growing season $\mathrm{ET}_{\mathrm{p}}$ trends were consistent with that of annual $\mathrm{ET}_{\mathrm{p}}$. Surprisingly, the annual and growing seasonal $\mathrm{ET}_{\mathrm{a}}$ of most vegetation types decreased consistently, and the downward trends were significant TMF, TMS and TGS. The SEBF was the only type that showed increased but not significant trends in both annual and growing season $\mathrm{ET}_{\mathrm{a}}$. In general, $\mathrm{ET}_{\mathrm{a}}$ and $\mathrm{ET}_{\mathrm{p}}$ showed inverse trends (i.e. positive trend for $\mathrm{ET}_{\mathrm{p}}$ with negative trend for $\mathrm{ET}_{\mathrm{a}}$ ) in the majority of types, for either annual or growing season (Table 5).

\subsection{NDVI responses across climatic gradients and vegetation types}

Correlation coefficients between TI-NDVI $\mathrm{g}$ and MGP (i.e. $\left.R_{(\text {NDVI-P) }}\right)$, TI-NDVI $g$ and AGDD (i.e. $\left.R_{(\text {NDVI-T) }}\right)$ were estimated for the 12 vegetation types using spatially-averaged 25 -yr time series data. $R_{\text {(NDVI-P) }}$ by vegetation type were plotted against MGP in Fig. $4 \mathrm{a}$, and $R_{\text {(NDVI-T) }}$ against AGDD in Fig. 4b.

Most ecosystems showed significant positive $R_{\text {(NDVI-P) }}$, except for subtropical evergreen broad-leaved forests (SEBF, $R=-0.09, P>0.05)$ and subtropical and tropical grassland (STG, $R=0.21, P>0.05$ ) (Fig. $4 \mathrm{a}$ ). The $R_{\text {(NDVI-P), when }}$ pooled together across the 12 vegetation types, showed a 
Table 3. Seasonal Mann-Kendall (SMK) trend tests of precipitation by vegetation type from 1982 to 2006.

\begin{tabular}{|c|c|c|c|c|c|c|c|c|c|c|c|c|}
\hline Vegetation & CTCF & TCF & $\mathrm{TMF}$ & TDBF & TDS & TMS & TGS & TG & STCF & STG & SDBF & SEBF \\
\hline \multicolumn{13}{|l|}{ Monthly } \\
\hline Jan & -0.3 & 0.8 & 0.0 & 0.4 & 0.0 & 1.0 & 0.9 & 0.7 & 0.0 & 1.0 & 0.5 & 0.4 \\
\hline Feb & 0.1 & 0.8 & -0.8 & -1.3 & -0.3 & -0.5 & -0.1 & 0.1 & 0.8 & -1.9 & 0.7 & -1.3 \\
\hline Mar & 0.2 & $-2.5^{b}$ & 0.0 & 1.1 & -1.5 & 0.8 & -0.9 & $-2.2^{\mathrm{a}}$ & $-2.2^{\mathrm{a}}$ & 0.3 & -1.2 & -1.3 \\
\hline Apr & -0.2 & 0.1 & -0.8 & -0.7 & -0.4 & 0.4 & 0.2 & 0.1 & -0.7 & -0.5 & 0.6 & 0.0 \\
\hline May & 0.5 & -1.7 & 0.0 & -0.5 & -1.4 & -0.6 & -0.4 & -1.1 & -0.6 & 1.4 & -0.9 & 0.4 \\
\hline Jun & -0.5 & 0.5 & -0.7 & -0.3 & 0.6 & -0.9 & -0.7 & 0.7 & -0.6 & 1.4 & 0.5 & 1.8 \\
\hline Jul & -1.0 & -0.3 & -0.7 & -0.2 & -0.5 & -1.0 & -1.4 & -0.7 & -1.0 & 0.7 & 0.7 & $2.1^{\mathrm{a}}$ \\
\hline Aug & $-2.7^{\mathrm{b}}$ & -0.4 & -1.4 & -0.9 & -1.6 & -1.8 & -1.9 & -0.7 & -0.8 & 0.5 & -0.2 & 1.1 \\
\hline Sep & -1.5 & 0.1 & $-2.4^{\mathrm{a}}$ & $-2.6^{\mathrm{b}}$ & $-2.8^{\mathrm{b}}$ & $-2.6^{b}$ & -1.7 & -0.8 & -1.0 & $-2.0^{\mathrm{a}}$ & -0.4 & $-2.3^{\mathrm{a}}$ \\
\hline Oct & 0.3 & -0.6 & 0.9 & 1.3 & 0.6 & 0.5 & -0.1 & -0.2 & 0.1 & -0.4 & -0.6 & -1.3 \\
\hline Nov & 0.4 & -0.6 & -0.7 & -0.3 & -0.4 & 0.0 & 0.1 & -0.2 & -1.4 & -1.3 & -0.3 & 0.5 \\
\hline Dec & 0.5 & 0.5 & -0.2 & 0.3 & 0.6 & 0.8 & 1.1 & 0.3 & 0.1 & 1.1 & 0.6 & -0.3 \\
\hline \multicolumn{13}{|c|}{ Growing season } \\
\hline MGP & $-2.1^{\mathrm{a}}$ & -1.0 & $-2.6^{b}$ & -1.0 & -1.7 & $-2.3^{\mathrm{a}}$ & $-2.3^{\mathrm{a}}$ & -0.9 & -1.6 & 0.0 & -0.7 & 1.3 \\
\hline $\begin{array}{l}\text { Annual } \\
\text { MAP }\end{array}$ & $-2.2^{\mathrm{a}}$ & -1.7 & $-2.1^{\mathrm{a}}$ & -1.3 & $-2.2^{\mathrm{a}}$ & $-2.2^{\mathrm{a}}$ & -1.1 & $-2.4^{\mathrm{a}}$ & 0.9 & 0.2 & $-2.1^{\mathrm{a}}$ & -0.8 \\
\hline
\end{tabular}

a Significant at $P<0.05{ }^{\mathrm{b}}$ Significant at $P<0.01$. A positive SMK statistic value denotes an upward trend and a negative one denotes a downward trend.

Table 4. Seasonal Mann-Kendall (SMK) trend tests of NDVI by vegetation type from 1982 to 2006.

\begin{tabular}{|c|c|c|c|c|c|c|c|c|c|c|c|c|}
\hline & $\mathrm{CTCF}$ & TCF & $\mathrm{TMF}$ & $\mathrm{TDBF}$ & TDS & TMS & TGS & $\mathrm{TG}$ & STCF & STG & SDBF & SEBF \\
\hline \multicolumn{13}{|l|}{ Monthly } \\
\hline Jan & -1.7 & 0.1 & -0.4 & -0.2 & 0.7 & -0.1 & -1.0 & -0.2 & 1.7 & -2.1 & 1.2 & -0.8 \\
\hline Feb & -0.9 & 0.8 & -0.2 & -0.1 & 0.8 & 0.1 & 0.1 & -0.1 & 1.5 & 0.3 & 0.9 & 0.0 \\
\hline Mar & -1.6 & 1.0 & $-3.0^{\mathrm{b}}$ & 0.1 & $2.2^{\mathrm{a}}$ & 1.6 & 1.5 & 0.5 & 1.1 & 0.6 & 0.2 & 0.1 \\
\hline Apr & 0.2 & 1.4 & -1.6 & $-2.1^{\mathrm{a}}$ & 0.6 & 1.8 & 1.2 & 1.4 & $3.2^{\mathrm{b}}$ & 1.8 & $3.3^{b}$ & 1.3 \\
\hline May & -0.2 & $2.2^{\mathrm{a}}$ & -0.3 & 1.7 & 1.9 & -0.6 & 0.2 & $3.6^{\mathrm{b}}$ & 1.5 & 1.3 & 1.4 & 0.9 \\
\hline Jun & -0.7 & -1.0 & -1.7 & $-2.2^{\mathrm{a}}$ & -0.7 & -0.9 & -1.3 & 0.7 & 0.3 & -1.7 & -0.6 & -1.9 \\
\hline Jul & -0.9 & $-2.4^{\mathrm{a}}$ & -0.7 & $-2.1^{\mathrm{a}}$ & 0.0 & 0.2 & 0.7 & 1.2 & -1.6 & -1.7 & -1.5 & $-2.3^{\mathrm{a}}$ \\
\hline Aug & 0.5 & -1.9 & -1.0 & -1.2 & 0.5 & $2.4^{\mathrm{a}}$ & $2.9^{\mathrm{b}}$ & 0.8 & -0.9 & $-2.8^{\mathrm{b}}$ & $-2.5^{\mathrm{a}}$ & $-3.5^{\mathrm{b}}$ \\
\hline Sep & 1.7 & -0.9 & 1.2 & 0.8 & 1.4 & 0.1 & 1.2 & 1.9 & -0.7 & -1.5 & -0.2 & $-2.2^{\mathrm{a}}$ \\
\hline Oct & 1.5 & 1.0 & -1.5 & 0.1 & 0.5 & -0.2 & -0.4 & 1.2 & 1.1 & -1.9 & 1.0 & -1.6 \\
\hline Nov & $-2.2^{\mathrm{a}}$ & 0.5 & -0.6 & -0.1 & 0.6 & -0.2 & 1.2 & -0.4 & 1.0 & 0.4 & 0.3 & 0.3 \\
\hline Dec & $-2.1^{\mathrm{a}}$ & 1.5 & -1.8 & -0.5 & 0.8 & -0.5 & 0.8 & 0.6 & 1.3 & 0.1 & -0.1 & 0.5 \\
\hline \multicolumn{13}{|c|}{ Growing season } \\
\hline Ti-NDVIg & 0.9 & $-2.0^{\mathrm{a}}$ & -1.2 & -1.3 & 1.4 & 0.3 & 1.1 & $2.2^{\mathrm{a}}$ & -0.7 & $-2.6^{\mathrm{b}}$ & -1.6 & $-3.3^{b}$ \\
\hline Annual & & & & & & & & & & & & \\
\hline Mean & -1.7 & 0.4 & $-2.8^{\mathrm{b}}$ & -1.3 & 1.6 & 1.0 & 1.6 & 1.8 & $2.1^{\mathrm{a}}$ & -1.8 & 0.6 & $-2.2^{\mathrm{a}}$ \\
\hline
\end{tabular}

a Significant at $P<0.05$. $^{\mathrm{b}}$ Significant at $P<0.01$. A positive SMK statistic value denotes an upward trend and a negative one denotes a downward trend.

strong linear relationship with MGP $\left(R^{2}=0.78, P<0.01\right)$. Collectively, the vegetation types of the NSTEC presented a significant decrease in $R_{\text {(NDVI-P) }}$ with increasing MGP. Unlike $R_{\text {(NDVI-P) }}, R_{\text {(NDVI-T) }}$ by all vegetation types were significantly positive. Comparatively, TGS demonstrated the lowest $R_{\text {(NDVI-T) }}$ but relatively high $R_{\text {(NDVI-P) }}$. As a whole, the $R_{\text {(NDVI-T) }}$ showed an insignificant negative and across-type relationship with $\operatorname{AGDD}\left(R^{2}=0.13, P=0.17\right)$.

\subsection{GWDI time trends by vegetation types}

TCF, TDS, TMS TGS and TG showed significantly higher average GWDI $(>2.0)$ than the rest of vegetation types during the study period. TGS $(\mathrm{GWDI}=7.9 \pm 0.8$ ) was the highest among all types (Fig. 5). The average GWDI of CTCF was close to 2.0 as the upper boundary of the semiarid/semihumid condition. In contrast, all subtropical and 
Table 5. Seasonal Mann-Kendall (SMK) trend tests of $\mathrm{ET}_{\mathrm{p}}$ and $\mathrm{ET}_{\mathrm{a}}$ by vegetation type from 1982 to 2006.

\begin{tabular}{|c|c|c|c|c|c|c|c|c|c|c|c|c|}
\hline & CTCF & TCF & TMF & TDBF & TDS & TMS & TGS & TG & STCF & STG & SDBF & SEBF \\
\hline \multicolumn{13}{|c|}{ Annual } \\
\hline $\mathrm{ET}_{\mathrm{p}}$ & $2.05^{\mathrm{a}}$ & 1.3 & -0.05 & 1.87 & 1.45 & $4.01^{\mathrm{b}}$ & 1.59 & $3.17^{\mathrm{b}}$ & 1.68 & -0.93 & 0.47 & 1.58 \\
\hline $\mathrm{ET}_{\mathrm{a}}$ & -1.73 & -1.49 & $-2.33^{\mathrm{a}}$ & -0.51 & $-1.96^{\mathrm{a}}$ & -1.77 & $-2.15^{\mathrm{a}}$ & -0.75 & $-2.15^{\mathrm{a}}$ & -0.09 & -0.37 & $2.1^{\mathrm{a}}$ \\
\hline \multicolumn{13}{|c|}{ Growing season } \\
\hline $\mathrm{ET}_{\mathrm{p}}$ & $1.96^{\mathrm{a}}$ & 0.14 & -0.18 & 1.16 & 0.32 & $3.5^{\mathrm{b}}$ & 1.35 & 1.45 & 0.18 & -1.21 & 0.23 & 1.02 \\
\hline $\mathrm{ET}_{\mathrm{a}}$ & -1.58 & -0.75 & $-2.05^{\mathrm{a}}$ & -0.65 & -1.73 & $-2.10^{\mathrm{a}}$ & $-2.14^{\mathrm{a}}$ & -0.47 & -1.49 & -1.35 & -1.02 & 1.26 \\
\hline
\end{tabular}

${ }^{\text {a }}$ Significant at $P<0.05$. ${ }^{\text {b }}$ Significant at $P<0.01$. A positive SMK statistic value denotes an upward trend and a negative one denotes a downward trend.
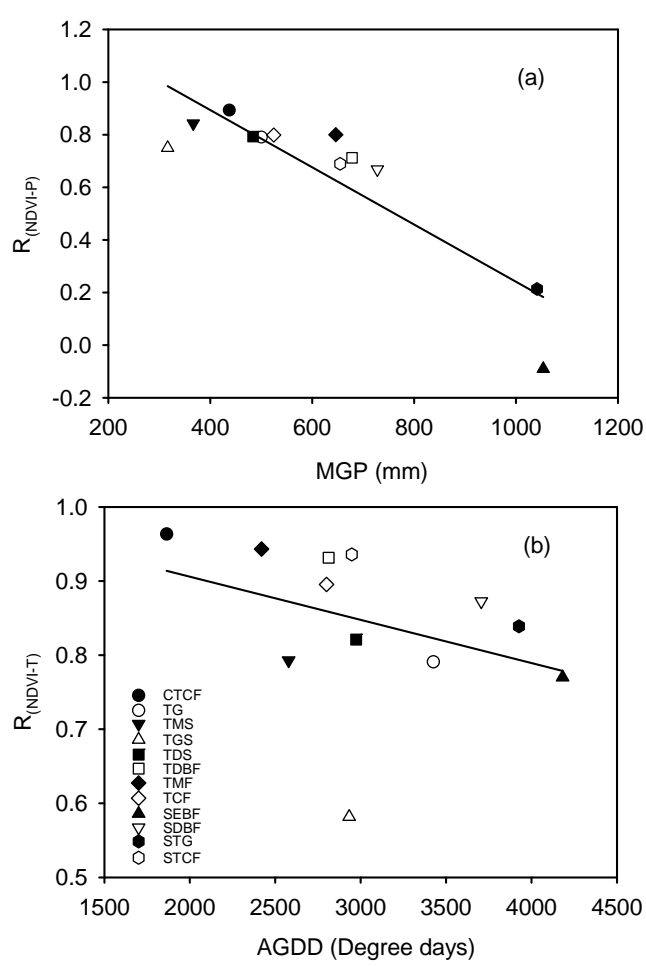

Fig. 4. (a) Relationship between mean growing season precipitation (MGP) and $R_{\text {(NDVI-P) }}$ (correlation coefficients between TI-NDVIg and MGP) $\left(R^{2}=0.78, P<0.01\right)$. Data are spatial means by vegetation type for the period 1982-2006. (b) Relationship between accumulated growing degree days (AGDD) and $R_{(\mathrm{NDVI}-\mathrm{T})}$ (correlation coefficients between TI-NDVI $\mathrm{g}_{\mathrm{g}}$ and AGDD) $\left(R^{2}=0.13, P=0.19\right)$. Data are spatial means by vegetation type for the period 1982-2006.

tropical types (STCF, SDBF, SEBF and STG) and two temperate types (TMF and TDBF) are considerably lower than the upper boundary of the equitant condition and even lower than the balance line (GWDI =1) with low variations. The sequence of bars from left to right in the graph (Fig. 5) roughly corresponds to the central latitude sequence of the vegetation types, distributed from north to south along the transect. So the figure meanwhile outlines the water deficit profile along the NSTEC from north to south.

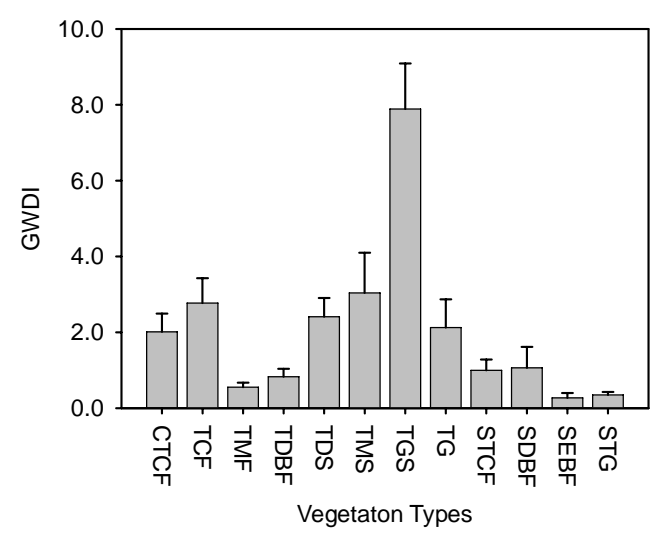

Fig. 5. Growing season water deficit index (GWDI) of different vegetation types. Data are spatial means for the period 1982-2006.

Among the twelve vegetation types, the cold temperate coniferous forest (CTCF) and the two temperate steppes (TGS and TMS) showed not only high interannual variations but also significant increasing trends $(P<0.05)$ during the study period (Fig. 6). The temperate coniferous forest, shrub and grassland (TCF, TDS and TG) showed substantial increases and high variations in GWDI. In contrast, the remaining two temperate types (TDBF and TMF) and all subtropical and tropical types (SEBF, SDBF, STG, and STCF) showed much lower and less variable GWDI; there were no significant trends except for TMF. Given that GWDI $=1.0$ is the baseline to differentiate water deficit condition: there was no water deficit in TMF, STG and SEBF during study period; there was periodically occurring water deficit in TDBF, SDBF and STCF; and there was severe and progressing water deficit in the rest of the vegetation types, notably in TGS.

\subsection{Associate GWDI with climate and vegetation activities}

For each individual vegetation type, GWDI was negatively and linearly related to MGP. However, the relationship differed among precipitation regions, and the slopes in arid and semiarid regions were significantly greater than those of humid and semihumid regions. When the data series of 

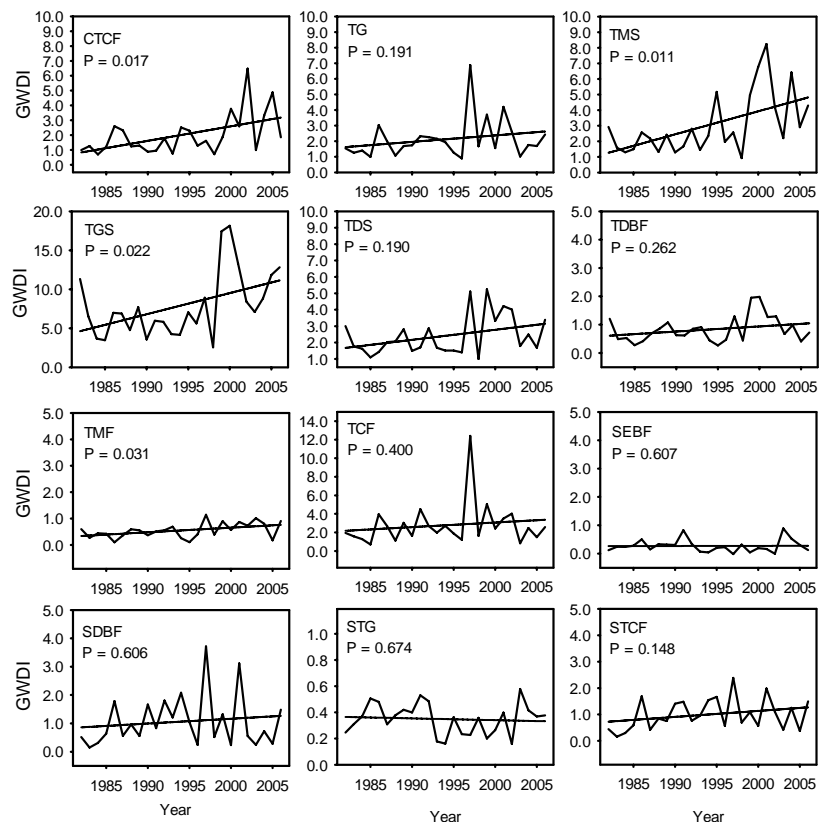

Year

Fig. 6. Time trends of growing season water deficit index (GWDI) for twelve vegetation types during 1982-2006. Data are spatial means by vegetation type. $P$ is the significance probability of the Mann-Kendall trend test.

all vegetation types were pooled, GWDI decreased in a hyperbolic fashion with increasing MGP (Fig. 7a). This is the expected cross-type GWDI-P response curve (Fig. 2). In the arid region $(\mathrm{MGP}<400 \mathrm{~mm}, \mathrm{GWDI}>2)$, the GWDI decreased sharply as the MGP increased from about $200 \mathrm{~mm}$ to $400 \mathrm{~mm}$. This region showed low variability among vegetations, including mainly herbaceous types (TGS, TMS, TDS and TCF). In the semiarid and semihumid region (medium precipitation region where MGP ranges from $400 \mathrm{~mm}$ to $700 \mathrm{~mm}, 0.5<$ GWDI $<2.0$ ), the GWDI decreased with dramatic variation among the types of TMF, TDBF, TCF, SDBF and CTCF. In the humid region (MGP $>700 \mathrm{~mm}$, GWDI $<0.5$ ), the slope was significantly lower than that of arid and medium precipitation regions. The three main vegetation types STG, STCF and SEBF showed low variability again (Fig. 7a). The GWDI balance line of 1.0 corresponded roughly to the MGP range of $500 \mathrm{~mm}$ to $700 \mathrm{~mm}$, with a median of $600 \mathrm{~mm}$.

Each individual vegetation type showed a positive relationship between GWDI and AGDD. There is no across-type trend in GWDI with increasing AGDD when the data series of all vegetation types were pooled (Fig. 7b). However, the slope coefficients of cold temperate and subtropical types are much lower than that of temperate regions. For example, there are significantly larger slopes in TGS, TMS and TDS compared with those of the subtropical vegetation types such as STCF, STG and SEBF (Fig. 7b). Moreover, the GWDI
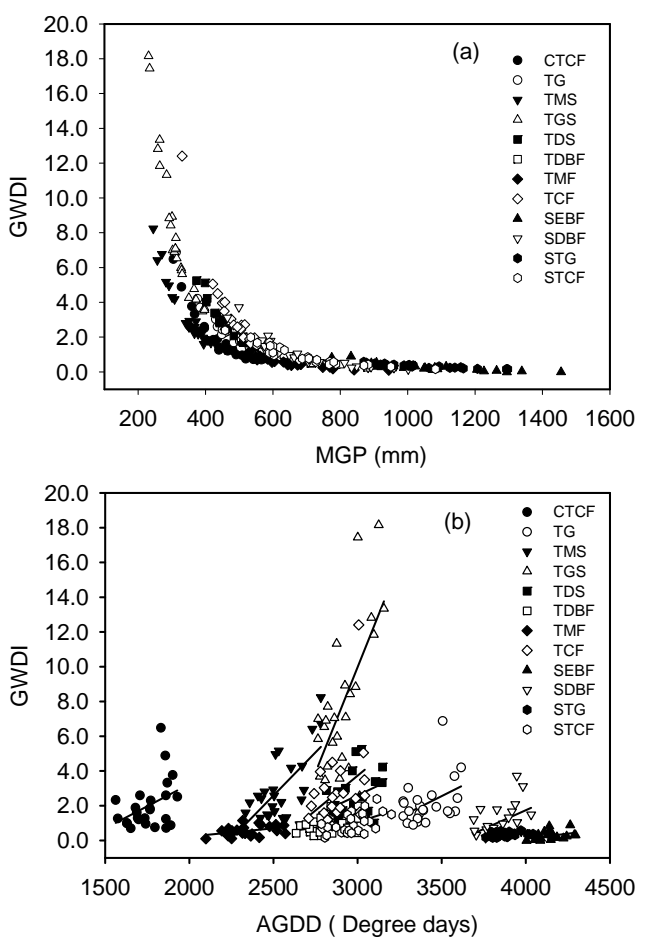

Fig. 7. The growing season water deficit index (GWDI) vs. (a) mean growing season precipitation (MGP) and (b) accumulated growing degree days (AGDD). All data are spatially averaged.

for temperate types also exhibited high interannual variability during the study period (Fig. 7b).

The GWDI showed a very strong relationship with TINDVI $_{\mathrm{g}}\left(r^{2}=0.82, P<0.05\right)$ when spatial and interannual means for 12 vegetation types were pooled (Fig. 8). The relationship was across-type and thus universal for associating vegetation activities with ecosystem water status. According to the relationship, the 12 vegetation types can be divided into three groups. The first group includes all four subtropical/tropical types (SEBF, SDBF, STG and STCF) and temperate deciduous broadleaf forest (TDBF), with reasonable water budget $(\mathrm{GWDI} \leq 1.0)$, on average during the study period. CTCF, TCF, TDS, TG and TMS belong to the second group that suffered from progressing water stress $(1.0<\mathrm{GWDI}<3.0)$. The most severe drought (GWDI $>3.0$ ) occurred in TGS. GWDI balance line 1.0 corresponds to TI-NDVI $I_{\mathrm{g}}$-value of 3.5 (Fig. 8). Therefore, the TI-NDVI $\mathrm{g}_{\mathrm{g}}$-value of 3.5 can be alternatively used as a NDVIbased threshold for fast evaluation on water deficit by remote sensing. 


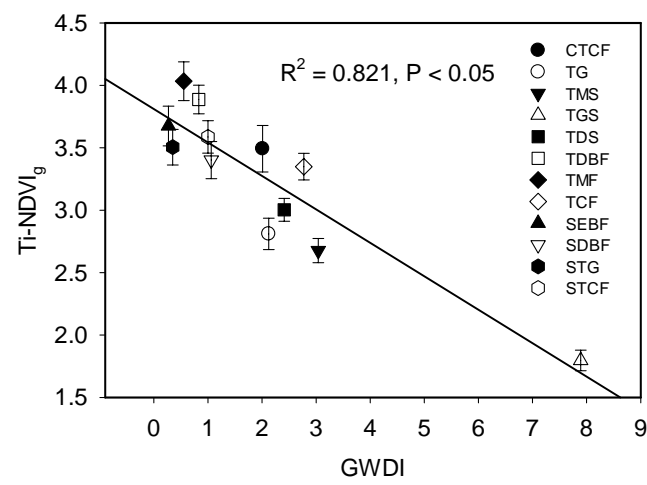

Fig. 8. Relationship between time-integrated growing season NDVI (TI-NDVI ${ }_{g}$ ) and growing season water deficit index (GWDI). Data are spatial averaged by vegetation type for the period 1982-2006.

\section{Discussion}

\subsection{Trends in climate, $\mathbf{E T}_{\mathrm{a}}$ and $\mathrm{ET}_{\mathrm{p}}$}

General trends in transect temperature found in our analysis are consistent with the warming trends presented by the 4th IPCC report chapter, during the similar time span of 1979 to 2005 (Trenberth et al., 2007). Our study showed that the highest temperature increase occurred in the mid-latitude area rather than in the northernmost area of the transect (Fig. 3b). Precipitation trend along the transect agrees with a prior study in China, that showed declines in annual precipitation over the past $50 \mathrm{yr}$ in northeast and northern China and increases in western China, Yangtze River area and along the southeast coast (Zhai and Pan, 2003). As whole, the NSTEC showed significant and consistent growing season declines in precipitation during the study period (Table 3).

Some previous studies suggested the potential intensification of the water cycle in the world attributed to warming (Held and Soden, 2000; Huntington, 2006; Zhang et al., 2009), however in our study, the majority of vegetation types along the transect decreased in their actual evapotranspiration despite their general upward trends in evaporative demand $\left(\mathrm{ET}_{0}\right)$. The divergent trends indicated that precipitation decline, particularly in the growing season, became the main limitation for most transect vegetations. It seems more likely that the water limiting on $\mathrm{ET}_{\mathrm{a}}$ was more than offset by the warming effect intensifying it, particularly for the middle and northern vegetation types (Table 3 ). On the contrary, for the humid south type SEBF, which was the only vegetation with increasing annual $\mathrm{ET}_{\mathrm{a}}$, the non-growing season warming has been the most obvious cause.

The vegetation-specific responses to climate trends were also reflected in the seasonality of photosynthetic activity and growing season length (Goetz et al., 2005), which are related to water assumption. The decreased vegetation activity change (NDVI as the proxy) in half transect forests types can be directly reflected by their downward $\mathrm{ET}_{\mathrm{a}}$ trends.
The consistent trends between growing season $\mathrm{ET}_{\mathrm{a}}$ and $\mathrm{TI}^{-N D V I} \mathrm{~g}$ indicated the rational interactions between climates and vegetations. However, the divergent trends between NDVI and $\mathrm{ET}_{\mathrm{a}}$ usually implies extreme climate conditions or trends. For example in CTCF, the abnormal growing season precipitation decline was the dominant limitation to forest growth, which was more than offset by the warming. Due to contrary reasons, the dry temperate grassland (TG), steppes (TMS, TGS) and shrubland (TDS) implied dominant control of growing season warming, showed upward TI-NDVI $g$ but downward growing season $\mathrm{ET}_{\mathrm{a}}$. Considering these four types have long suffered from growing season precipitation decline and were in arid and semiarid regions (Figs. 5 and 6), we speculated the upward trend of TI-NDVI $g$ was the effect of dramatic warming on prolonging growing season length. This agrees with some previous studies that non-forest type phenology is more susceptible to warming (Piao et al., 2006a; Yu et al., 2010). Another reason for the disagreement between NDVI and $\mathrm{ET}_{0}$ trends was that we used evapotranspiration instead of plant transpiration, which is more closely correlated to vegetation activities. ET component participation is important particularly for low coverage vegetations, because the soil evaporation and interception evaporation may result in the inconsistent trends in $\mathrm{ET}_{\mathrm{a}}$ and plant transpiration. In general, we agreed the main limitation of ET in these four types was water (McVicar et al., $2012 \mathrm{~b}$ ), because $\mathrm{ET}_{0}$ in these types were considerably high. Increasing vegetation activity may not be beneficial to vegetations, particularly for those in face of water deficit, which may create excessive deep soil water loss, result in decreased overall moisture availability for plants (Bradley and Mustard, 2008), and thus decrease vegetation activities for the future. Our result on the $\mathrm{ET}_{\mathrm{a}}$ trend in cold temperate coniferous forests (CTCF) agreed with the recent study that showed a decreasing trend in the boreal forest of northern Mongolia (Zhang et al., 2009).

\subsection{Trend in vegetation activity}

The positive trend in TI-NDVI $I_{\mathrm{g}}$ for the entire transect (Fig. 3c) agreed with Fang et al. (2003, 2004), who showed vegetation activity increased in China during 1982 to 1999. The vegetation activity increase was apparent in middle- and high-latitude areas, and was in accord with the spatial pattern of warming (Fig. 3a), which played an important role in plant growth and lengthening the growing season (Piao et al., 2006a, b). Our previous research found that the growing season lengths of most vegetation types in the NSTEC were prolonged during the period 1982-2006 (Yu et al., 2010). Although precipitation decreased in the whole transect, particularly in the middle-latitude region, the warming effect on NDVI was more than offset by decreasing water availability. Specifically, in the arid and semiarid regions, the greening trend can be attributed to the prolonged growing season length. 
However, each individual vegetation type showed differential response to environment forcing. The downward TI$\mathrm{NDVI}_{\mathrm{g}}$ trends in all temperate forests (TCF, TMF and TDBF) can be attributed to the MGP decline (Table 3). Regarding the high-latitude cold temperate forest (CTCF), it seemed that the strong growing season warming effect on vegetation activity was more than offset by the winter cooling and precipitation decline (Tables 2-4). Our overall analysis on CTCF, including $\mathrm{ET}_{\mathrm{a}}$, precipitation and GWDI, agreed with the recent study of boreal forests in northern Mongolia, which showed a browning trend because of increasing water deficit (Zhang et al., 2009). Our findings indicate that high-latitude regions are particular susceptive to warming, which may to a great extent compensate for the water deficit effect on vegetation activities.

Middle-latitude temperate deciduous shrub (TDS) and three non-woody types, TMS, TGS and TG, in the middle and higher latitude areas experienced not only warming but also growing season precipitation decline. As discussed above, it seemed that temperature-related growing season length increase played a more important role than water deficit in dominating the greening trend in this area. Piao et al. (2006b) suggested that the TMS and TGS exhibited significant upward trends on NDVI during a shorter time span of 1982-1998. However, our study showed insignificant upward trends in these two types during a longer time span of 1982 to 2006. Interestingly, these two studies may indicate a decreasing pace of greening as a result of warming, particularly during the most recent nine years (1998-2006) within the study period. The decreased pace of greening in these two herbaceous types was likely due to progressing water deficit, resulted mainly from the continuing precipitation decline (Table 3).

Subtropical types including STCF, STG, SDBF and SEBF demonstrated consistent summer decline in TI-NDVI $\mathrm{g}$, from roughly June to August (Table 4). The STG, SDBF and SEBF meanwhile showed consistent precipitation increase in summer (Table 3). Therefore, we speculate the summer browning was most likely due to decreases in surface solar radiation associated with significant decline in sunshine duration (Wang et al., 2009). Similarly, Ren et al. (2005) also suggested a decline in sunshine duration in southeast China during the past $50 \mathrm{yr}$ since 1951 . It is worthy to note that the significant browning trends in STG and SEBF were suggestive of decreasing potential of carbon sequestration in these areas, which were usually identified as the most significant natural carbon sinks (Leake, 2008).

\subsection{Differential vegetation response to climate variability along transect gradients}

Linear decrease in $R_{\text {(NDVI-P) }}$ with increasing MGP $\left(R^{2}=\right.$ $0.78, P<0.01)$ was found across vegetation types that distribute from dry to wet regions along the NSTEC (Fig. 4a). The across-type "gradient effect" indicated a decrease effect of precipitation exerting controls on vegetation activity. The result agreed with previous study in the semiarid area that suggested the NDVI-rainfall relationship was linear in 200$600 \mathrm{~mm}$ annual precipitation, and changed from scattered to dispersed when rainfall was higher than $600 \mathrm{~mm}$ (Martiny et al., 2006). In our study, $\mathrm{TI}^{-N_{D V I}}$ for ten vegetation types had been found significantly correlated with growing season precipitation within $750 \mathrm{~mm}$, and poorly correlated when MGP was above $1000 \mathrm{~mm}$. These results indicated the water availability, as a limitation to evapotranspiration and thus plant growth, had changed with other factors such as radiation or wind speed, i.e "energy limitation" (McVicar et al., 2012b). In contrast, there was no significant "gradient effect" in temperature affecting on NDVI. Although the warming effect on vegetation appeared to be not statistically different among vegetation types along the transect, the greening trends in the arid and semiarid north transect regions indicated the warming effect on vegetation was more than offset by increasing "water limitation". However, in extreme dry condition, the warming effect will decrease dramatically, for instance, the $R_{(\mathrm{NDVI}-\mathrm{T})}$ in TGS was much lower than other types (Fig. 4b). The browning trends in the humid south transect regions indicated the warming effect was less than offset by the increasing "energy limitation" as a result of decreasing wind speed (McVicar et al., 2012a) and sunshine duration (Ren et al., 2005).

\subsection{GWDI and ecosystem susceptibility to climate change}

The main advantage of using GWDI is that it captures not only the meteorological variables related to atmospheric evaporative demand $\left(\mathrm{ET}_{\mathrm{p}}\right)$, but also the actual vegetation water assumption $\left(\mathrm{ET}_{\mathrm{a}}\right)$. Unlike the aridity index $(\mathrm{AI})$ defined as the ratio of $P / \mathrm{ET}_{\mathrm{p}}$ (Budyko, 1974), GWDI explicitly takes $\mathrm{ET}_{\mathrm{a}}$ into account; therefore, the index allows for better diagnosis of ecosystem water balance, which may be suggestive of long-term vegetation activity change. Because the GWDI assumes precipitation as the main source of water input and $\mathrm{ET}_{0}$ as the main output, it associates closely with ecosystem green water (Liu et al., 2009; Liu and Yang, 2010). In addition, this index enables us to quickly evaluate the possibility that the ecosystem produces blue water (Calder, 2005; Falkenmark and Rockström, 2006).

Based only on NDVI trend analysis, few earlier studies suggested a reverse desertification process in Chinese arid and semiarid regions, which include our study region of TGS (Runnström et al., 2000; Zhong and Qu, 2003). Similarly, we also found a similar upward though not significant trend of the NDVI in TGS during our study period (Table 4). However, the extreme high GWDI and dramatic upward trend in TGS indicated an evident drying trend during the study period. The continuing decrease of overall moisture availability may reduce vegetation activity and finally lead to ecosystem degradation. The speculation has been evidenced 
by some previous findings that suggested grassland desertification within the region of temperate grass steppe (TGS) (e.g. Tong et al., 2002). Therefore, it is more likely that the desertification reversal process only reflected the provisional phenomenon of plant phonological response to warming. The abrupt greening may accelerate water loss through plant transpiration, given the water deficit status continued. Inferred from their upward trends in GWDI (Fig. 6), the shrubland (TDS) and three non-woody types (TG, TMS, TGS) may become susceptible to future climate change, particularly precipitation decline, evidenced by the decreasing pace of greening (discussed above). These results are quite similar to a recent study in shrubland and grassland biomes where abrupt greening was often followed by gradual browning (De Jong et al., 2012). There was no water deficit in TDBF, TMF, SDBF, SEBF, STCF and STG according to their low GWDI and interannual variability during the study period. However, the increasing trends and interannual variation in CTCF and TCF can be attributed to MGP decline. CTCF and TCF were identified as the two forests facing progressive risk of water deficit, because their GWDI broke the upper boundary of 2.0 and became variable. Low water availability became the main constraint of vegetation activity in the two types.

The strong intra- and across-type relationships between GWDI and MGP reflected the dominant effect of precipitation on ecosystem water deficit, but the hyperbolic fashion meanwhile indicated a fast decrease of the effect. Comparatively, the dry region showed higher interannual variation in GWDI than the wet region, due likely to an increasing uncertainty in $\mathrm{ET}_{\mathrm{a}}$ that attributes to drought. Regarding the intertype variation, herbaceous types either in dry or wet regions demonstrated higher GWDI than forests. This phenomenon was likely a result of $\mathrm{ET}_{\mathrm{a}}$ overestimating for low coverage vegetations. The MGP median of $600 \mathrm{~mm}$ can be a baseline to differentiate "water limitation" and "energy limitation" vegetation types. The arid region types showed much higher slope coefficients in their AGDD-GWDI relationships than those of humid region (Fig. 7b). It seemed that the warming effect on vegetation became variable and uncertain with the progressing seasonal water deficit.

The strong relationship between TI-NDVI $\mathrm{g}_{\mathrm{g}}$ and GWDI reflected the strong interaction between ecosystem water balance and its vegetation activity. In addition, GWDI proved to be effective in indicating vegetation activities for diverse vegetation types in broad environmental conditions. The baselines in both TI-NDVI $\mathrm{g}$ (3.5) and GWDI (1.0) can be used to evaluate water status for the different vegetation types. Through the baseline, we identified that the TDS, TG and TMS had suffered from increasing water deficit, and severe drought occurred in TGS (Fig. 8). Most forests were in roughly hydrological equilibrium status during the study period except for CTCF and TCF, whose increasing water deficit and decreasing vegetation activity suggested their rising susceptibility to future climate change.

\section{Conclusions}

The whole transect exhibited high spatial heterogeneity and interannual variability in terms of climate change pattern during the period 1982-2006. This study found significant warming trends accompanied by general precipitation decline for the majority of vegetation types, thus the growing season water deficit became the main constraint to $\mathrm{ET}_{\mathrm{a}}$ in the majority of transect vegetation, despite of the increased atmospheric evaporative demand $\left(\mathrm{ET}_{0}\right)$.

Warming and growing season water deficit exert counteracting impacts on vegetation activity. The northernmost transect forest (CTCF), temperate steppes (TGS, TMS), grass (TG) and shrub (TDS) are more susceptive to warming, as temperature-related growing season length increasingly plays a more important role than offset by water deficit in dominating NDVI trend, but in dry conditions, the warming effect on NDVI decreases significantly. We speculate the greening trends may reverse if the water deficit continues, and thus are susceptive to climate change. The increasing growing season water deficit poses increasing challenges to the activity of temperate forests (TMF, TCF and TDBF), inferred from their browning trends accompanied by decreasing $\mathrm{ET}_{\mathrm{a}}$. By contrast, the browning trends in subtropical types (STCF, STG, SDBF and SEBF) were due to increasing summer cloudiness.

GWDI represents the ecohydrological equilibrium of an ecosystem, and its long-term trend holds clues about vegetation susceptibility to environmental change. According to GWDI and TI-NDVI $\mathrm{g}_{\mathrm{g}}$ trends, CTCF, TCF, TDS, TG, TMS have suffered from increasing water deficit, and severe drought occurred in TGS. On average, most forests were hydrologically balanced during the study period. However, the emerging water deficit and browning in cold temperate and temperate forests (CTCF, TCF) suggested their rising susceptibility to future climate change.

Acknowledgements. This research was jointly supported by Special Research Program for Public-welfare Forestry (No. 200804001 and No. 201104006), Chinese Academy of Forestry Foundation (CAFYBB2008007), National Nature Science Foundation of China (30590383) and the Key Laboratory of Forest Ecology and Environment of State Forestry Administration. The authors would like to thank the editor and anonymous reviewers for their numerous comments, suggestions, and grammatical corrections that improved an earlier draft of this paper.

Edited by: J. Liu 


\section{References}

Allen, R. G., Pereira, L. S., Raes, D., and Smith, M.: Crop Evapotranspiration - Guidelines for Computing Crop Water Requirements, FAO Irrigation and Drainage Paper 56, Rome, Italy, 1998.

Andréassian, V.: Waters and forests: from historical controversy to scientific debate, J. Hydrol., 291, 1-27, 2004.

Arora, V. K.: The use of the aridity index to assess climate change effect on annual runoff, J. Hydrol., 265, 164-177, 2002.

Beck, H. E., McVicar, T. R., Van Dijk, A. I. J. M., Schellekens, J., de Jeu, R. A. M., and Bruijnzeel, L. A.: Global evaluation of four AVHRR-NDVI data-sets: Intercomparison and assessment against Landsat imagery, Remote Sens. Environ., 115, 25472563, doi:10.1016/j.rse.2011.05.012, 2011.

Beurs, K. M. and Henebry, G. M.: Trend Analysis of the Pathfinder AVHRR Land (PAL) NDVI data for the deserts of central Asia, IEEE Geosci. Remote S., 1, 282-286, 2004.

Bradley, B. A. and Mustard, J. F.: Comparison of phenology trends by land cover class: a case study in the Great Basin, USA, Glob. Change Biol., 14, 334-346, doi:10.1111/j.13652486.2007.01479.x, 2008.

Brown, A. E., Zhang L., McMahon, T. A., Western, A. W., and Vertessy, R. A.: A review of paired catchment studies for determining changes in water yield resulting from alterations in vegetation, J. Hydrol., 310, 28-61, 2005.

Brown, T. C., Hobbins, M. T., and Ramirez, J. A.: Spatial distribution of water supply in the coterminous United States, J. Am. Water Resour. As., 44, 1474-1487, 2008.

Budyko, M. I.: Climate and Life, International Geophysics Series, 18, Academic, New York, 508 pp., 1974.

Calder, I. R.: Blue Revolution: Integrated Land and Water Resource Management, Earthscan, London, 2005.

Chen, J., Wang, C., Jiang, H., Mao, L., and Yu, Z.: Estimating soil moisture using Temperature-vegetation Dryness Index (TVDI) in the Huang-huai-hai (HHH) plain, Int. J. Remote Sens., 32, 11651177, 2011.

De Jong, R., Verbesselt, J., Schaepman, M. E., and De Bruin, S.: Trend changes in global greening and browning: contribution of short-term trends to longer-term change, Glob. Change Biol., 18, 642-655, 2012.

Donohue, R. J., Roderick, M. L., and McVicar, T. R.: On the importance of including vegetation dynamics in Budyko's hydrological model, Hydrol. Earth Syst. Sci., 11, 983-995, doi:10.5194/hess11-983-2007, 2007.

Donohue, R. J., McVicar, T. R., and Roderick, M. L.: Climaterelated trends in Australian vegetation cover as inferred from satellite observations, 1981-2006, Glob. Change Biol., 15, 10251039, 2009.

Donohue, R. J., Roderick, M. L., and McVicar, T. R.: Roots, storms and soil pores: Incorporating key ecohydrological processes into Budyko's hydroclimatic framework, J. Hydrol., 436-437, 35-50, 2012.

Dragoni, D., Schmid, H. P., Wayson, C. A., Potter, H., Grimmond, C. S. B., and Randolph, J. C.: Evidence of increased net ecosystem productivity associated with a longer vegetated season in a deciduous forest in south-central Indiana, USA, Glob. Change Biol., 17, 886-897, 2011.

Falkenmark, M. and Rockström, J.: The new blue and green water paradigm: Breaking new ground for water resources planning and management, J. Water Res. Pl.-ASCE, 132, 129-132, 2006.
Fang, J. Y., Piao, S. L., and Field, C. B.: Increasing net Primary Production in China From 1982 to 1999, Front. Ecol. Environ., 1, 293-297, 2003.

Fang, J. Y., Piao, S. L., He, J. S., and Ma, W. H.: Increasing terrestrial vegetation activity in China, 1982-1999, Sci. China Ser.-C, 47, 229-240, 2004.

Goetz, S. J., Bunn, A. G., Fiske, G. J., and Houghton, R. A.: Satellite observed photosynthetic trends across boreal North America associated with climate and fire disturbance, P. Natl. Acad. Sci. USA, 102, 13521-13525, 2005.

Held, I. M. and Soden, B. J.: Water vapor feedback and global warming, Earthscan, London, Annu. Rev. Energ. Env., 25, 441475, 2000

Hundecha, Y. and Bárdossy, A.: Modeling of the effect of land use changes on the runoff generation of a river basin through parameter regionalization of a watershed model, J. Hydrol., 292, 281-295, 2004.

Huntington, T. G.: Evidence for intensification of the global water cycle: Review and synthesis, J. Hydrol., 319, 83-95, 2006.

Hutchinson, M. F. and Gessler, P. E.: Splines-More Than Just a Smooth Interpolator, Geoderma, 62, 45-67, 1994.

IPCC: Climate Change 2007: Mitigation, Contribution of Working Group III to the Fourth Assessment Report of the Intergovernmental Panel on Climate Change, edited by: Metz, B., Davidson, O. R., Bosch, P. R., Dave, R., and Meyer, L. A., Cambridge University Press, Cambridge, United Kingdom and New York, NY, USA, 2007.

Jia, G. J., Epstein, H. E., and Walker, D. A.: Spatial heterogeneity of tundra vegetation response to recent temperature changes, Glob. Change Biol., 12, 42-55, 2006.

Lavabre, J., Sempere, D., and Cernesson, F.: Changes in the hydrological response of a small Mediterranean basin a year after a wildfire, J. Hydrol., 142, 273-299, 1993.

Leake, J. E.: "Biosphere carbon stock management: Addressing the threat of abrupt climate change in the next few decades", by Peter Read, an editorial comment, Climatic Change, 87, 329-334, doi:10.1007/s10584-007-9385-6, 2008.

Liu, J. and Yang, H.: Spatially explicit assessment of global consumptive water uses in cropland: green and blue water, J. Hydrol., 384, 187-197, 2010.

Liu, J., Zehnder, A. J. B., and Yang H.: Global consumptive water use for crop production: The importance of green water and virtual water, Water Resour. Res., 45, W05428, doi:10.1029/2007WR006051, 2009.

Martiny, N., Camberlin, P., Richard, Y., and Philippon, N.: Compared regimes of NDVI and rainfall in semi-arid regions of Africa, Int. J. Remote Sens., 27, 5201-5223, 2006.

McVicar, T. R. and Bierwirth, P. N.: Rapidly assessing the 1997 drought in papua new guinea using composite AVHRR imagery, Int. J. Remote Sens., 22, 2109-2128, 2001.

McVicar, T. R., Niel, T. G. V., Li, L., Hutchinson, M. F., Mu, X., and Liu, Z.: Spatially distributing monthly reference evapotranspiration and pan evaporation considering topographic influences, J. Hydrol., 338, 196-220, 2007.

McVicar, T. R., Van Niel, T. G., Roderick, M. L., Li, L. T., Mo, X. G., Zimmermann, N. E., and Schmatz, D. R.: Observational evidence from two mountainous regions that near-surface wind speeds are declining more rapidly at higher elevations than lower elevations: 1960-2006, Geophys. Res. Lett., 37, L06402, 
doi:10.1029/2009GL042255, 2010.

McVicar, T. R., Roderick, M. L., Donohue, R. J., Li, L. T., Van Niel, T. G., Thomas, A., Grieser, J., Jhajharia, D., Himri, Y., Mahowald, N. M., Mescherskaya, A. V., Kruger, K. C., Rehman, S., and Dinpashoh, Y.: Global review and synthesis of trends in observed terrestrial near-surface wind speeds: Implications for evaporation, J. Hydrol., 416-417, 182-205, 2012a.

McVicar, T. R., Roderick, M. L., Donohue, R. J., and Van Niel, T. G.: Less bluster ahead? Overlooked ecohydrological implications of global trends of terrestrial near surface wind speeds, Ecohydrology, 5, 381-388, doi:10.1002/eco.1298, 2012b.

Méndez-Barroso, L. A., Vivoni, E. R., Watts, C. J., and Rodríuez, J. C.: Seasonal and interannual relations between precipitation, surface soil moisture and vegetation dynamics in the North American monsoon region, J. Hydrol., 377, 59-70, 2009.

Mu, Q., Heinsch, F. A., Zhao, M., and Running, S. W.: Development of a global evapotranspiration algorithm based on MODIS and global meteorology data, Remote Sens. Environ., 111, 519-536, 2007.

Myneni, R. B., Keeling, C. D., Tucker, C. J., Asrar, G., and Nemani, R. R.: Increased plant growth in the northern high latitudes from 1981 to 1991, Nature, 386, 698-702, 1997.

Nemani, R. R., Keeling, C. D., Hashimoto, H., Jolly, W. M., Piper, S. C., Tucker, C. J., Myneni, R. B., and Running, S. W.: Climate driven increases in global terrestrial net primary production from 1982 to 1999, Science, 300, 1560-1563, 2003.

Niehoff, D., Fritsch, U., and Bronstert, A.: Land-use impacts on storm-runoff generation: scenarios of land-use change and simulation of hydrological response in a meso-scale catchment in SW-Germany, J. Hydrol., 267, 80-93, 2002.

Patel, N. R., Anapashsha, R., Kumar, S., Saha, S. K., and Dadhwal, V. K.: Assessing potential of MODIS derived temperature/vegetation condition index (TVDI) to infer soil moisture status, Int. J. Remote Sens., 30, 23-39, 2009.

Piao, S., Fang, J., Zhou, L., Ciais, P., and Zhu, B.: Variations in satellite-derived phenology in China's temperate vegetation, Glob. Change Biol., 12, 672-685, 2006a.

Piao, S., Mohammat, A., Fang, J., Qiang, C., and Feng, J.: NDVIbased increase in growth of temperate grasslands and its responses to climate changes in China, Global Environ. Chang., 16, 340-348, 2006b.

Prasad, A. K., Sarkar, S., Singh, R. P., and Kafatos, M.: Inter-annual variability of vegetation cover and rainfall over India, Adv. Space Res., 39, 79-87, 2006.

Prasad, A. K., Singh, R. P., Tare, V., and Kafatos, M.: Use of vegetation index and meteorological parameters for the prediction of crop yield in India, Int. J. Remote Sens., 28, 5207-5235, 2007.

Ren, G. Y., Guo, J., Xu, M. Z., Chu, Z. Y., Zhang, L., Zou, X. K., Li, Q. X., and Liu, X. N.: Climate changes of mainland China over the past half century (in Chinese), Acta Meteorol. Sin., 63, 942-956, 2005.

Rhee, J., Im, J., and Carbone, G. J.: Monitoring agricultural drought for arid and humid regions using multi-sensor remote sensing data, Remote Sens. Environ., 114, 2875-2887, 2010.

Richard, Y., Martiny, N., Fauchereau, N., Reason, C., Rouault, M., Vigaud, N., and Tracol, Y.: Interannual memory effects for spring NDVI in semi-arid South Africa, Geophys. Res. Lett., 35, L13704, doi:10.1029/2008GL034119, 2008.
Runnström, M. C.: Is northern China winning the battle against desertification? Satellite remote sensing as a tool to study biomass trends on the Ordos plateau in semiarid China, Ambio, 29, 468476, 2000.

Scheiter, S. and Higgins, S. I.: Impacts of climate change on the vegetation of Africa: an adaptive dynamic vegetation modelling approach, Glob. Change Biol., 15, 2224-2246, 2009.

Sun, G., McNulty, S. G., Lu, J., Amatya, D. M., Liang, Y., and Kolka, R. K.: Regional annual water yield from forest lands and its response to potential deforestation across the southeastern United States, J. Hydrol., 308, 258-268, 2005.

Sun, G., Zhou, G., Zhang, Z., Wei, X., McNulty, S. G., and Vose, J. M.: Potential water yield reduction due to forestation across China, J. Hydrol., 328, 548-558, 2006.

Sun, G., Caldwell, P., Noormets, A., McNulty, S. G., Cohen, E., Myers, J. M., Domec, J., Treasure, E., Mu, Q., Xiao, J., Ranjeet, J., and Chen, J.: Upscaling key ecosystem functions across the conterminous United States by a water-centric ecosystem model, J. Geophys. Res., 116, 1-16, 2011.

Sun, P., Liu, S., Jiang, H., Lü, Y., Liu, J., Lin, Y., and Liu, X.: Hydrologic effects of NDVI time series in a context of climatic variability in an Upstream Catchment of the Minjiang River, J. Am. Water Resour. As., 44, 1132-1143, 2008.

Suzuki, R., Xu, J., and Motoya, K.: Global analyses of satellitederived vegetation index related to climatological wetness and warmth, Int. J. Climatol., 26, 425-438, 2006.

Tan, S. Y.: The influence of temperature and precipitation climate regimes on vegetation dynamics in the US Great Plains: a satellite bioclimatology case study, Int. J. Remote Sens., 28, 49474966, 2007.

Thomas, A.: Development and properties of 0.25-degree gridded evapotranspiration data fields of China for hydrological studies, J. Hydrol., 358, 145-158, 2008.

Tong, C., Hao, D. Y., Gao, X., Jiang, Q. H., and Yong, S. P.: Forecast on changes of steppe degradation patterns in the Xilin River Basin, Inner Mongolia: an application of Markov process, Journal of Natural Resources, 17, 488-493, 2002 (in Chinese).

Trenberth, K. E., Jones, P. D., Ambenje, P., Bojariu, R., Easterling, D., Klein Tank, A., Parker, D., Rahimzadeh, F., Renwick, J. A., Rusticucci, M., Soden, B., and Zhai, P.: Observations: surface and atmospheric climate change. in: climate change 2007: the physical science basis. contribution of working group I to the fourth assessment report of the intergovernmental panel on climate change, edited by: Solomon, S., Qin, D., Manning, M., Chen, Z., Marquis, M., Averyt, K. B., Tignor, M., and Miller, H. L., Cambridge University Press, Cambridge, United Kingdom and New York, NY, USA, 2007.

Tucker, C. J. and Sellers, P. J.: Satellite remote sensing of primary vegetation, Int. J. Remote Sens., 7, 1395-1416, 1986.

Wang, L., D’Odorico, P., Evans, J. P., Eldridge, D. J., McCabe, M. F., Caylor, K. K., and King, E. G.: Dryland ecohydrology and climate change: critical issues and technical advances, Hydrol. Earth Syst. Sci., 16, 2585-2603, doi:10.5194/hess-16-25852012, 2012.

Wang, Y. J., Huang, Y., and Zhang, W.: Changes in surface solar radiation in mainland China over the period from 1961 to 2003, Climatic and Environmental Research, 14, 405-413, 2009 (in Chinese). 
Wei, X. and Zhang, M.: Quantifying stream flow change caused by forest disturbance at a large spatial scale: a single watershed study, Water Resour. Res., 46, W12525, doi:10.1029/2010WR009250, 2010.

White, M. A., Thornton, P. E., and Running, S. W.: A Continental phenology model for monitoring vegetation responses to interannual climatic variability, Global Biogeochem. Cy., 11, 217-234, 1997.

White, M. A., Hoffman, F., and Hargrove, W.: A global framework for monitoring phenological response to climate change, Geophys. Res. Lett., 32, L04705, doi:10.1029/2004GL021961, 2005.

Yu, Z., Sun, P. S., and Liu, S. R.: Phenological change of main vegetation types along a North-south transect of eastern China, Chinese Journal of Plant Ecology, 34, 316-329, 2010 (in Chinese).

Zang, C. F., Liu, J., van der Velde, M., and Kraxner, F.: Assessment of spatial and temporal patterns of green and blue water flows under natural conditions in inland river basins in Northwest China, Hydrol. Earth Syst. Sci., 16, 2859-2870, doi:10.5194/hess-162859-2012, 2012.

Zeng, Z., Liu, J., Koeneman, P. H., Zarate, E., and Hoekstra, A. Y.: Assessing water footprint at river basin level: a case study for the Heihe River Basin in northwest China, Hydrol. Earth Syst. Sci., 16, 2771-2781, doi:10.5194/hess-16-2771-2012, 2012.

Zhai, P. and Pan, X.: Trends in temperature extremes during 1951-1999 in China, Geophys. Res. Lett., 30, 1913, doi:10.1029/2003GL018004, 2003.
Zhang, K., Kimball, J. S., Mu, Q., Jones, L. A., Goetz, S. J., and Running, S. W.: Satellite based analysis of northern ET trends and associated changes in the regional water balance from 1983 to 2005, J. Hydrol., 379, 92-110, 2009.

Zhang, L., Dawes, W. R., and Walker, G. R.: Predicting the effect of vegetation changes on catchment average water balance, Cooperative Research Centre for Catchment Hydrology, Technical Report 99/12, 1-2, 1999.

Zhang, L., Dawes, W. R., and Walker, G. R.: Response of mean annual evapotranspiration to vegetation changes at catchment scale, Water Resour. Res., 37, 701-708, 2001.

Zhang, Y. K. and Schilling, K. E.: Increasing stream flow and base flow in Mississippi river since the 1940s: effect of land use change, J. Hydrol., 24, 412-422, 2006.

Zhao, M. and Running, S. W.: Drought-induced reduction in global terrestrial net primary production from 2000 through 2009, Science, 329, 940-943, doi:10.1126/science.1192666, 2010.

Zhao, M., Fu, C., Yan, X., and Wen, G.: Study on the relationship between different ecosystems and climate in China using NOAA/AVHRR data, Acta Geogr. Sin., 56, 287-296, 2001.

Zhong, D. C. and Qu, J. J.: Recent developmental trend and prediction of sand deserts in China, J. Arid Environ., 53, 317-329, 2003. 